\title{
Nitidumpeptins A and B, Cyclohexapeptides Isolated from Zanthoxylum nitidum var. tomentosum: Structural Elucidation, Total Synthesis, and Antiproliferative Activity in Cancer Cells
}

Feng Qin, ${ }^{\dagger, \#}$ Cai Yi Wang, ${ }^{\ddagger, \#}$ Donghwa Kim, ${ }^{\ddagger}$ Heng-Shan Wang, ${ }^{\dagger}$ Yan-Kui Zhu, ${ }^{\dagger}$

Sang Kook Lee, ${ }^{*}$, Gui-Yang Yao, ${ }^{*}, \dagger, \S$ and Dong Liang ${ }^{*}, \dagger$

${ }^{\dagger}$ State Key Laboratory for Chemistry and Molecular Engineering of Medicinal

Resources, Collaborative Innovation Center for Guangxi Ethnic Medicine, School of

Chemistry and Pharmaceutical Sciences, Guangxi Normal University, Guilin 541004,

People's Republic of China

${ }^{\ddagger}$ Natural Products Research Institute, College of Pharmacy, Seoul National University,

Seoul 08826, Republic of Korea

${ }^{\S}$ Institut für Chemie, Technische Universität Berlin, Strasse des 17. Juni 124, 10623

Berlin, Germany

*Email: liangdonggxnu@163.com (D. L.); sklee61@snu.ac.kr (S. K. L.); guiyang.yao@chem.tu-berlin.de (G. Y.) 


\section{Table of Contents}

Figure S1. Interaction of molecular modeling between YAP and compound 2...........................

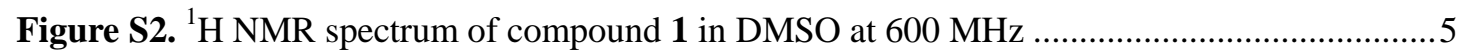

Figure S3. ${ }^{13} \mathrm{C}\left\{{ }^{1} \mathrm{H}\right\}$ NMR spectrum of compound $\mathbf{1}$ in DMSO at $150 \mathrm{MHz}$...............................

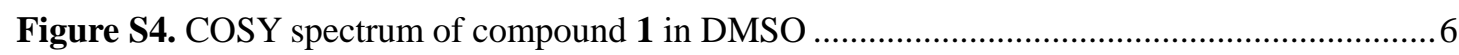

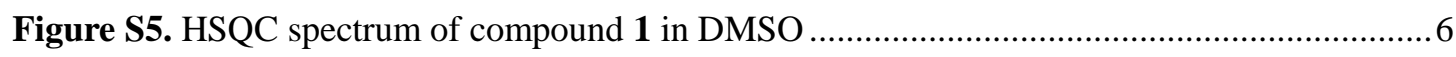

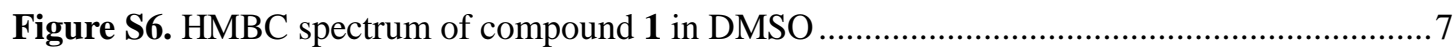

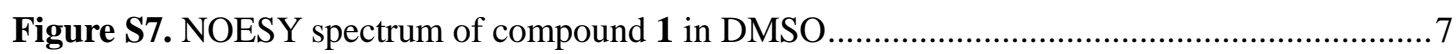

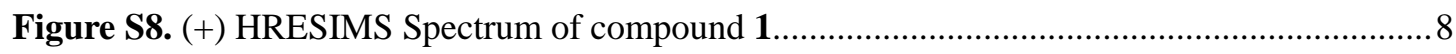

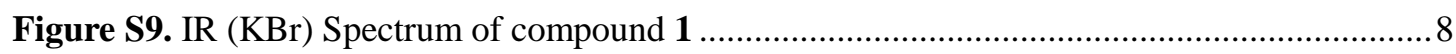

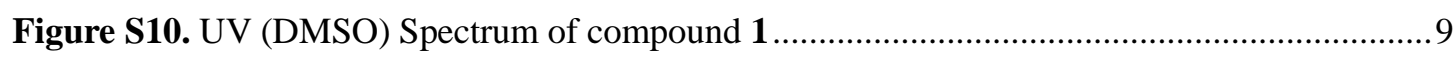

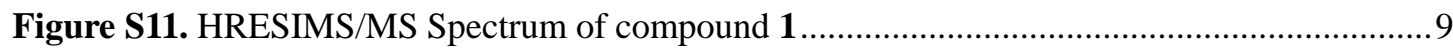

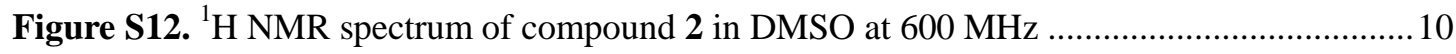

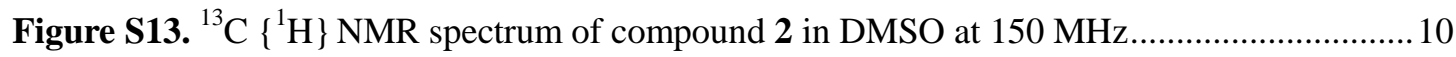

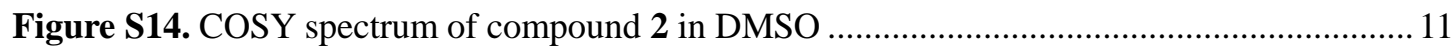

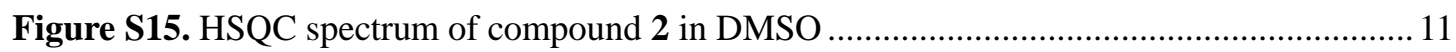

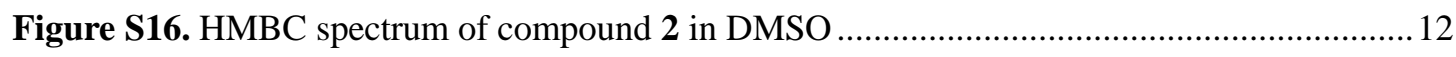

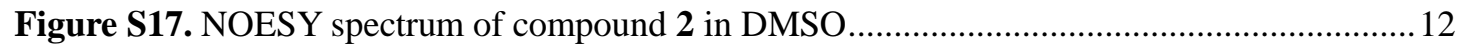

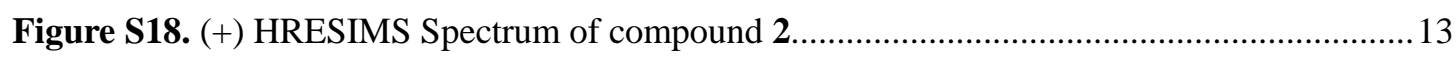

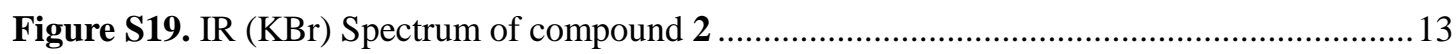

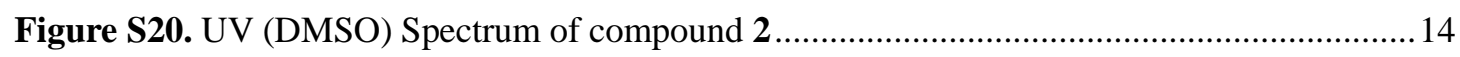

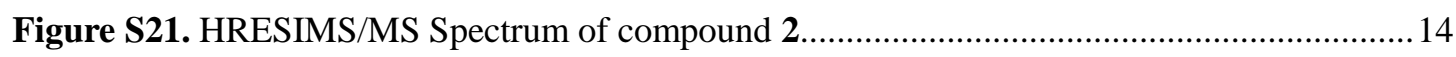

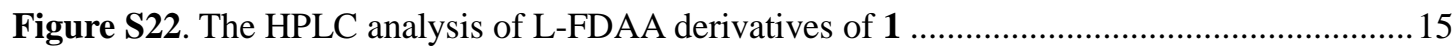

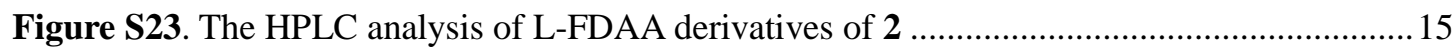

Figure S24. The HPLC analysis of L-FDAA derivatives of standard amino acids.(c) L-Asp, (d)

D-Asp, (e) L-Ala, (f) D-Ala, (g) L-Ile, (h) D-Ile, (i)L-Phe, (j) D-Phe ........................................... 17

Figure S25. ${ }^{1}$ H NMR comparison of natural Nitidumpeptin A (below) and synthetic one (above)

Figure S26. ${ }^{13} \mathrm{C}\left\{{ }^{1} \mathrm{H}\right\}$ NMR comparison of natural Nitidumpeptin A (below) and synthetic one (above)

Figure S27. ${ }^{1} \mathrm{H}$ NMR comparison of natural Nitidumpeptin B (below) and synthetic one (above)

Figure S28. ${ }^{1} \mathrm{H}$ NMR spectrum of compound 3 in DMSO at $400 \mathrm{MHz}$...................................... 19

Figure S29. ${ }^{13} \mathrm{C}\left\{{ }^{1} \mathrm{H}\right\}$ NMR spectrum of compound 3 in DMSO at $100 \mathrm{MHz}$............................20

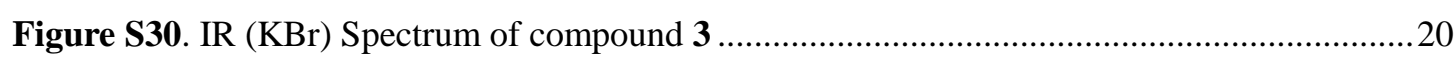

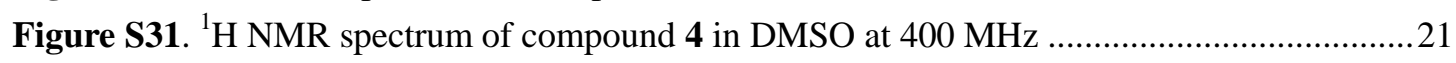

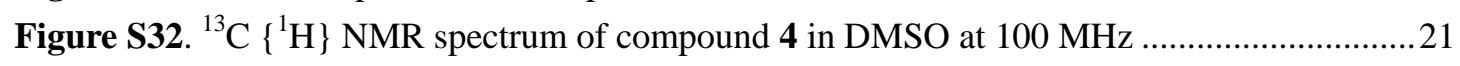

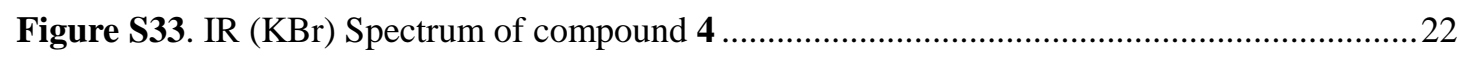

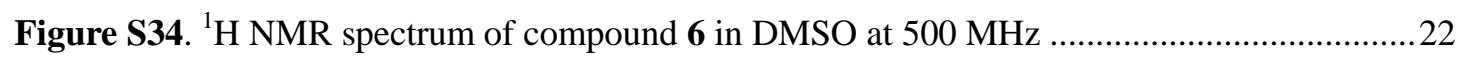

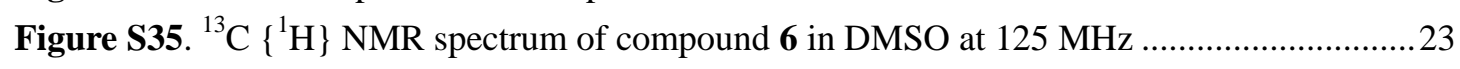

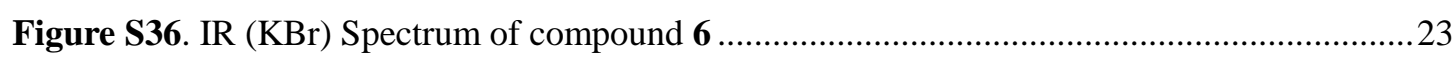

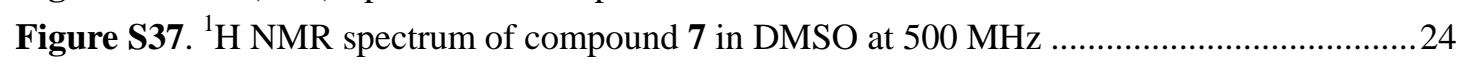

Figure S38. HSQC-ed $\left\{{ }^{1} \mathrm{H}_{-}{ }^{13} \mathrm{C}\right\}$ spectrum of compound 7 in DMSO at $500 \mathrm{MHz}$......................24 


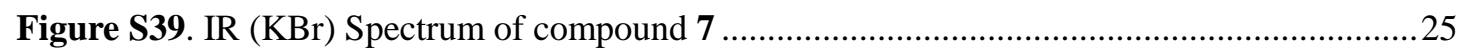

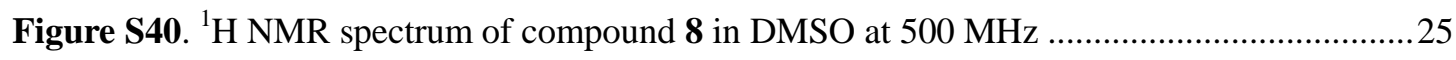

Figure S41. HSQC-ed $\left\{{ }^{1} \mathrm{H}^{13}{ }^{13} \mathrm{C}\right\}$ spectrum of compound 8 in DMSO at $500 \mathrm{MHz}$......................26

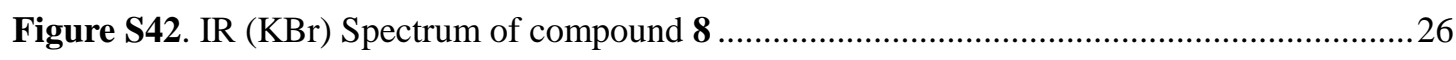

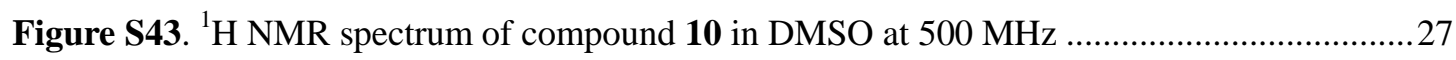

Figure S44. HSQC-ed $\left\{{ }^{1} \mathrm{H}^{13}{ }^{13} \mathrm{C}\right\}$ spectrum of compound 10 in DMSO at $500 \mathrm{MHz}$...................2

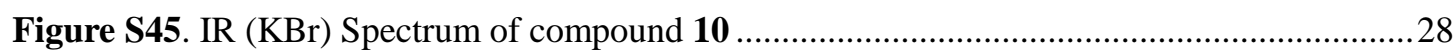




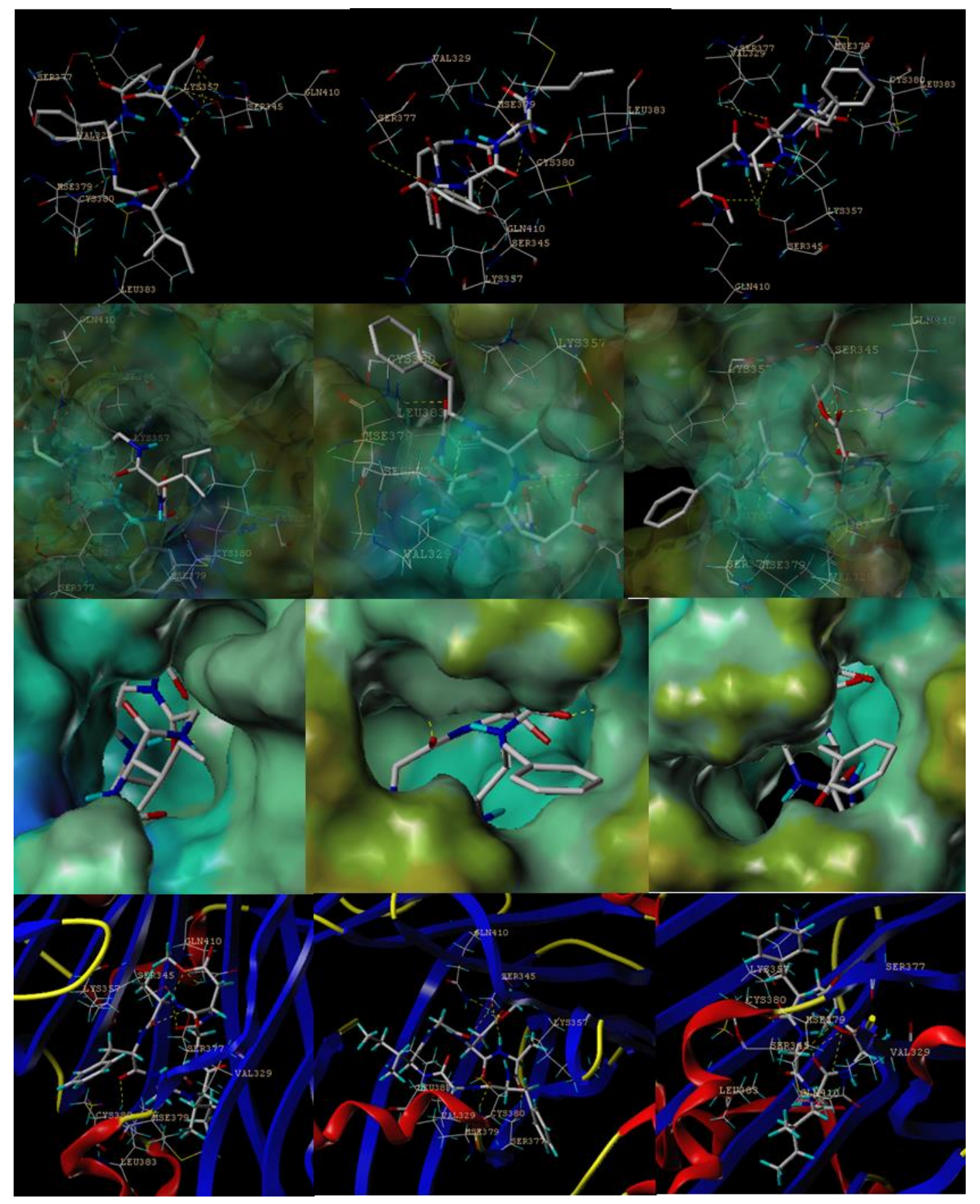

Figure S1. Interaction of molecular modeling between YAP and compound 2

The binding model of compounds 2 in complex with YAP. The proposed binding mode and interaction of molecular modelling between YAP and compounds 2 . 


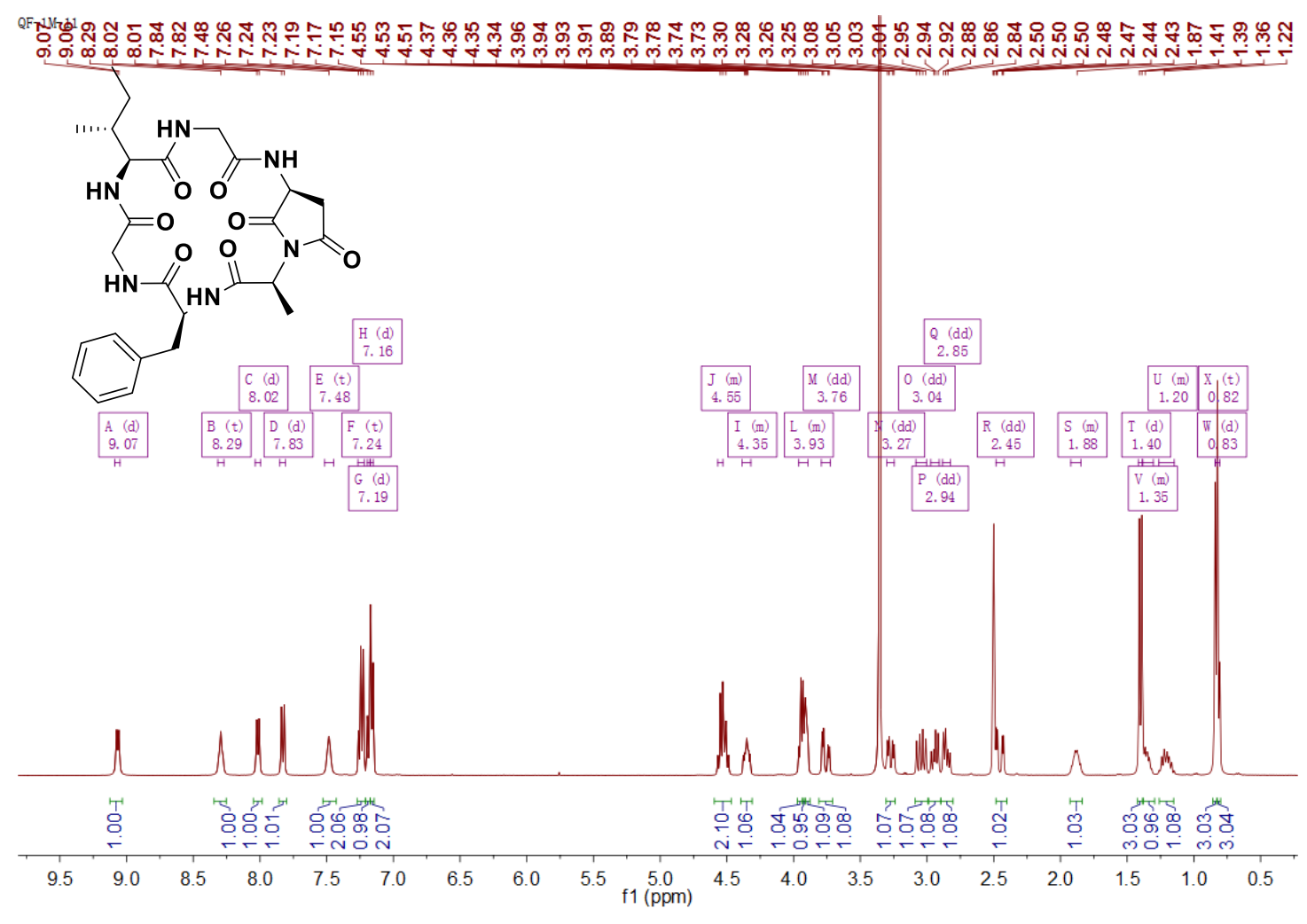

Figure S2. ${ }^{1} \mathrm{H}$ NMR spectrum of compound 1 in DMSO at $600 \mathrm{MHz}$
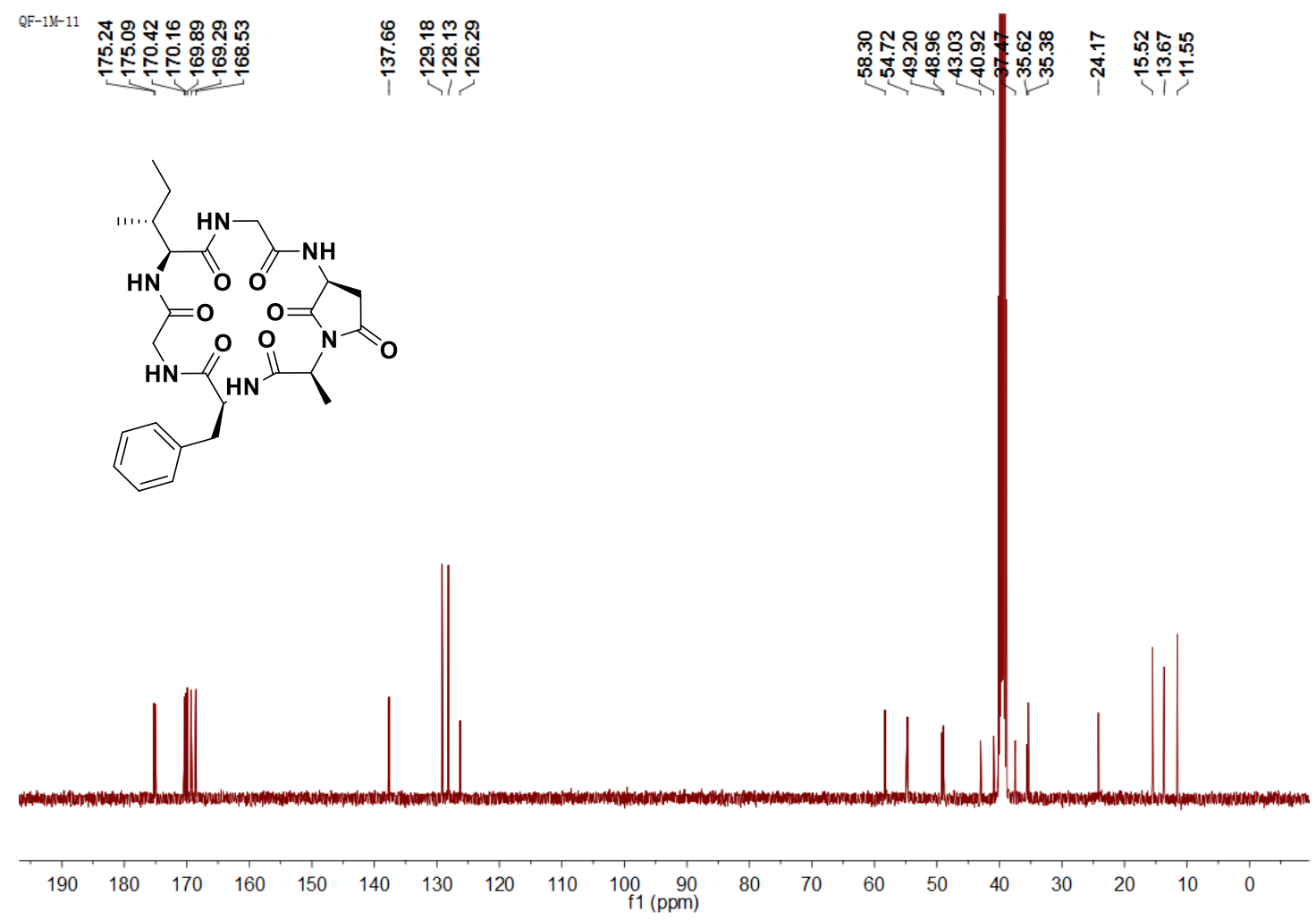

Figure S3. ${ }^{13} \mathrm{C}\left\{{ }^{1} \mathrm{H}\right\}$ NMR spectrum of compound 1 in DMSO at $150 \mathrm{MHz}$ 


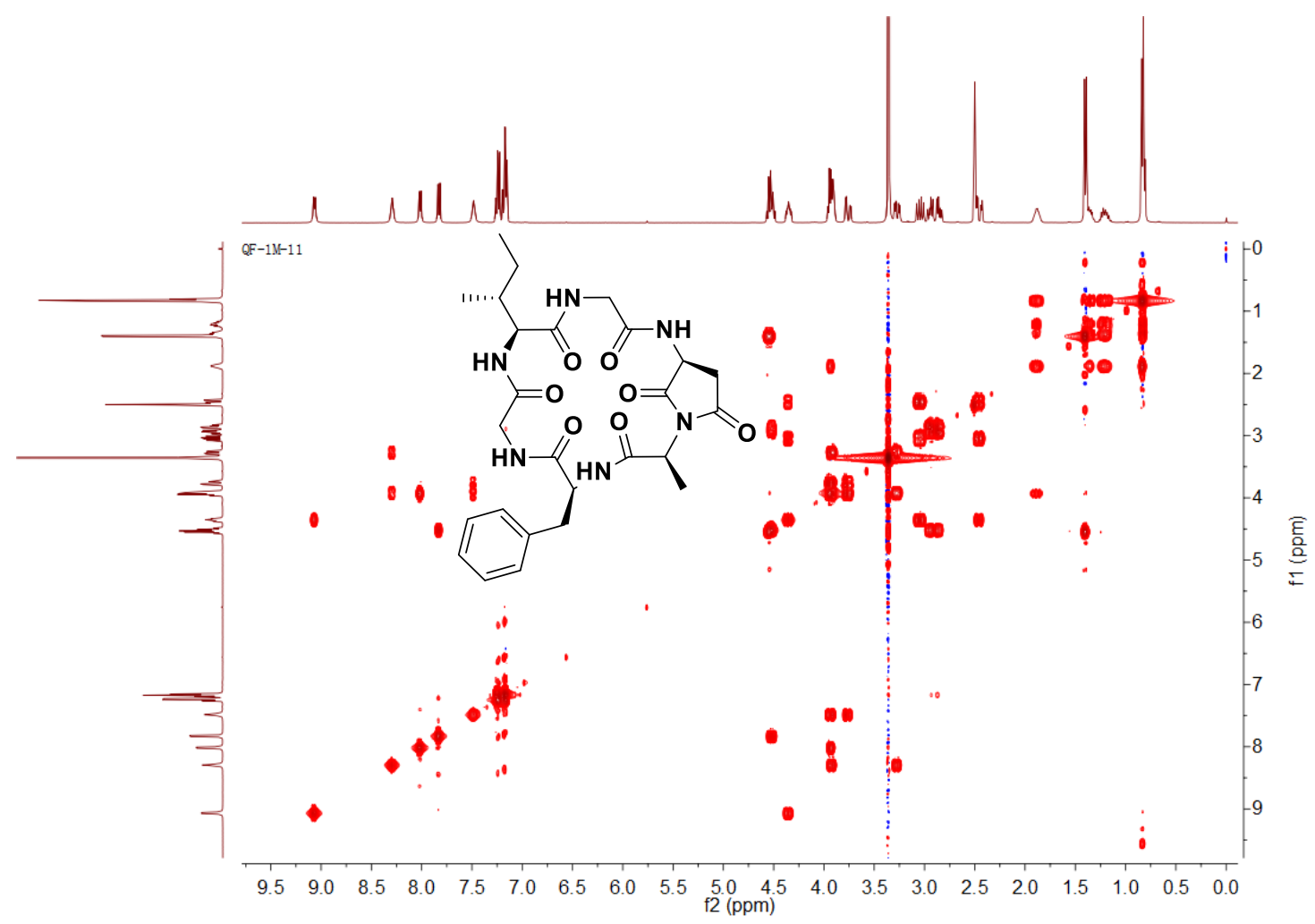

Figure S4. COSY spectrum of compound 1 in DMSO

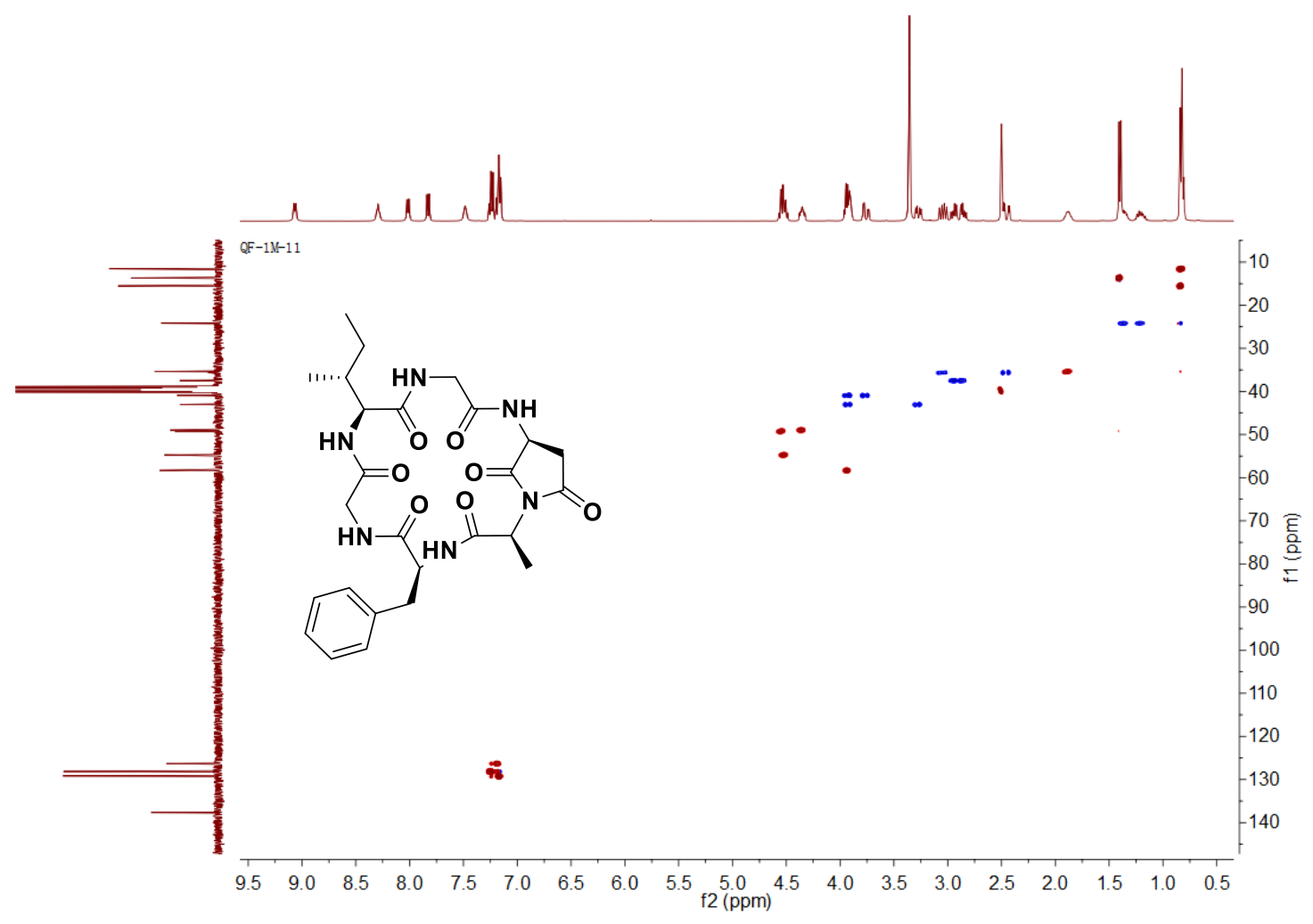

Figure S5. HSQC spectrum of compound 1 in DMSO 


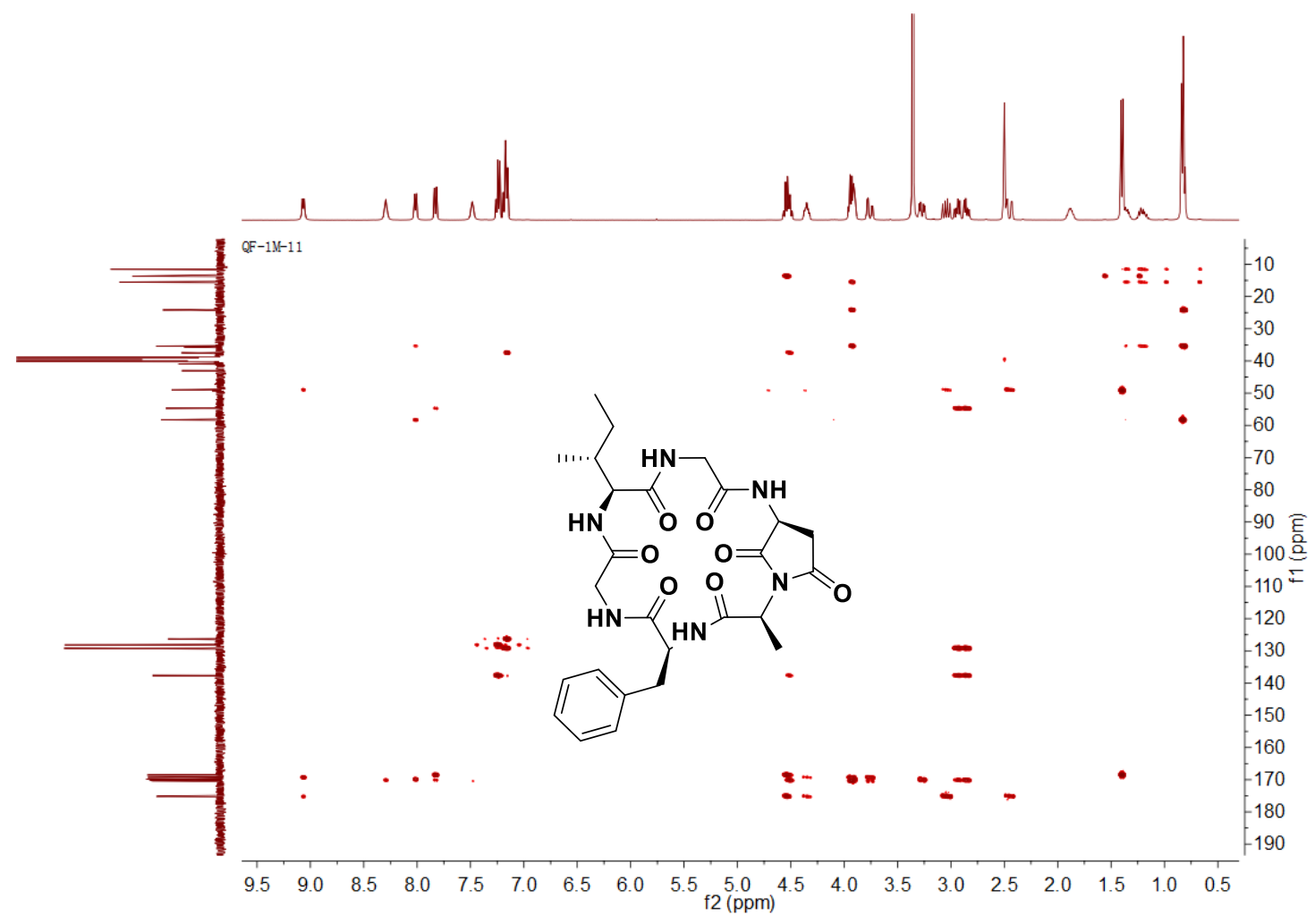

Figure S6. HMBC spectrum of compound 1 in DMSO

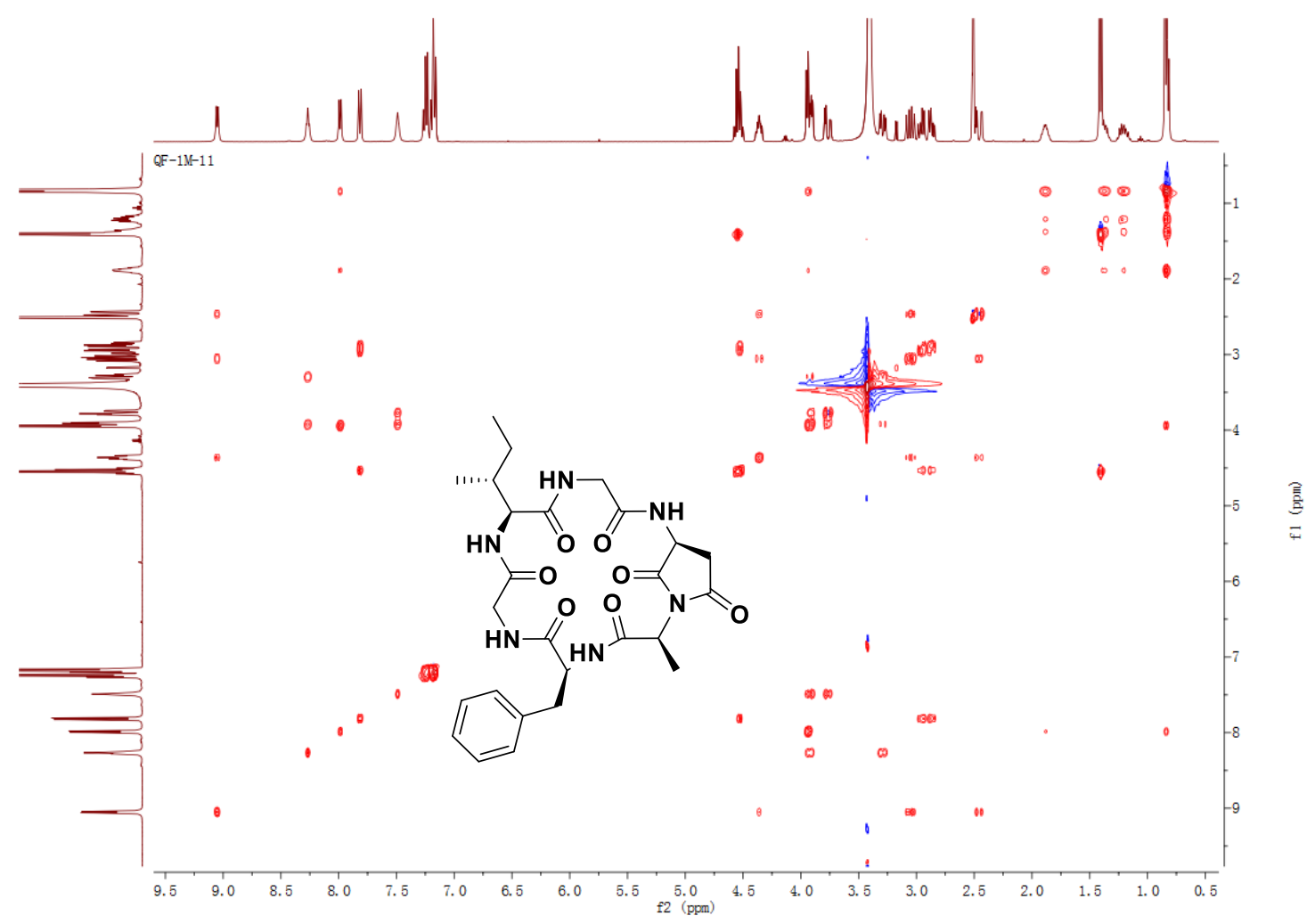

Figure S7. NOESY spectrum of compound 1 in DMSO 


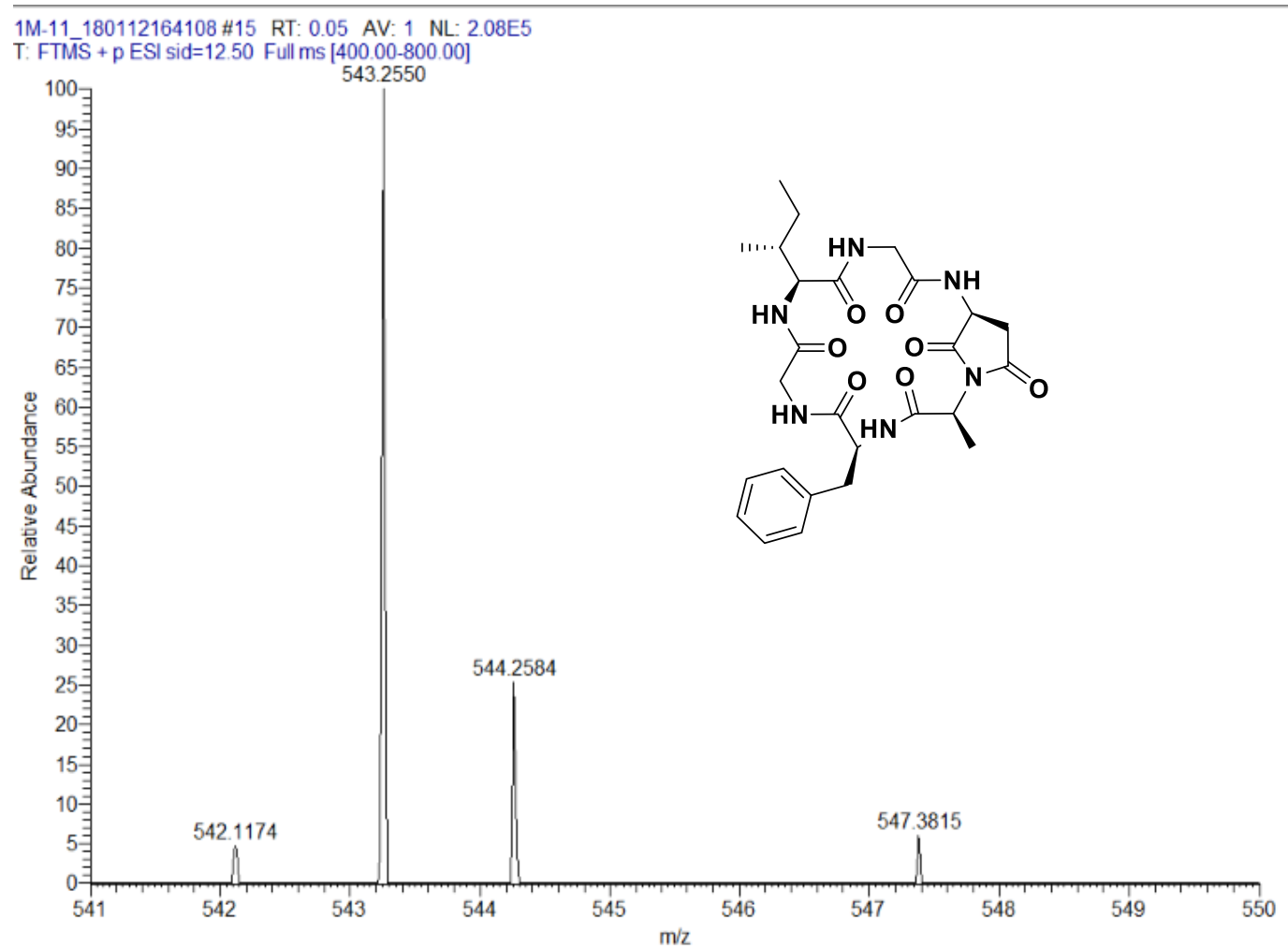

Figure S8. (+) HRESIMS Spectrum of compound 1

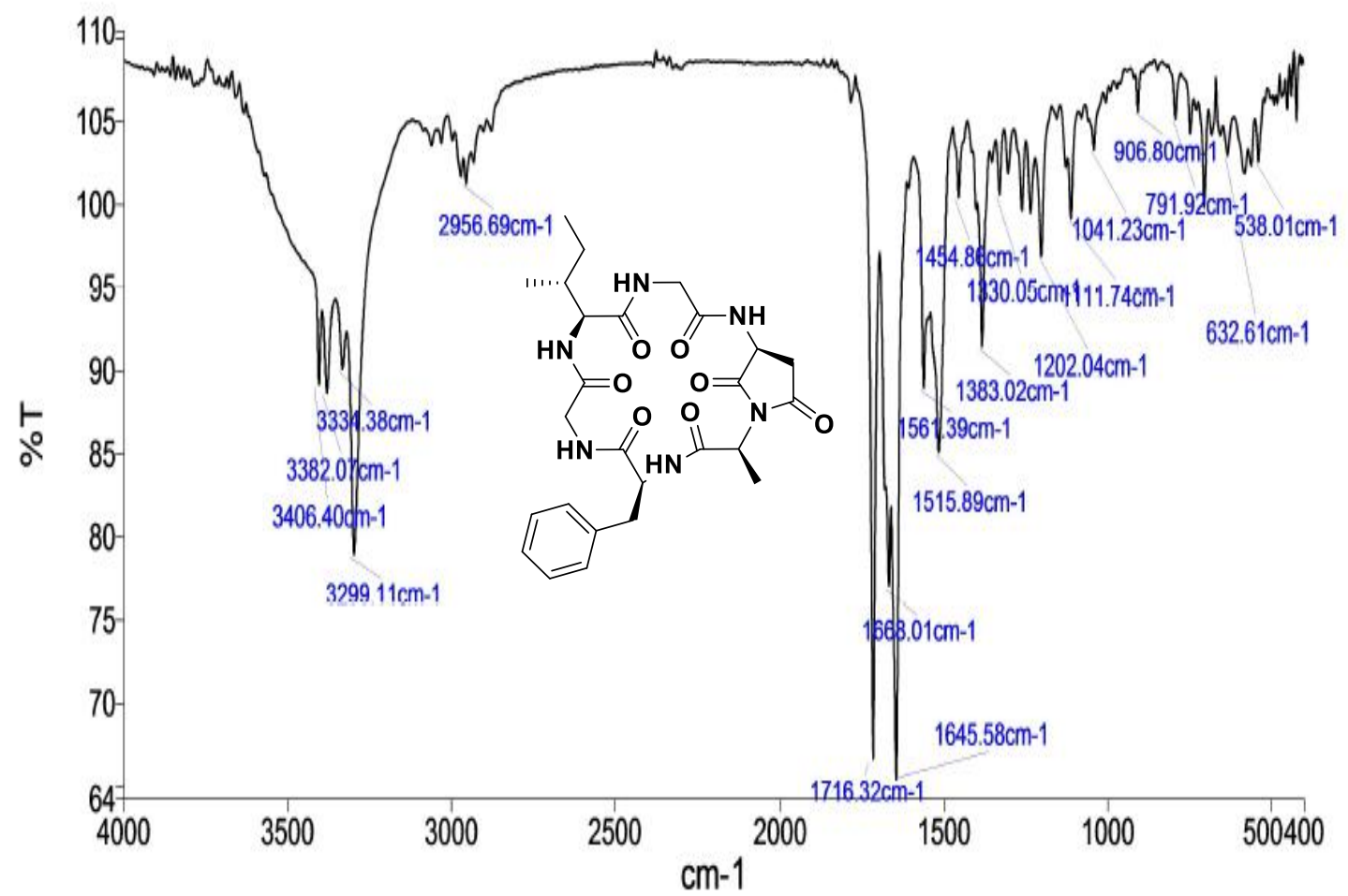

Figure S9. IR (KBr) Spectrum of compound 1 


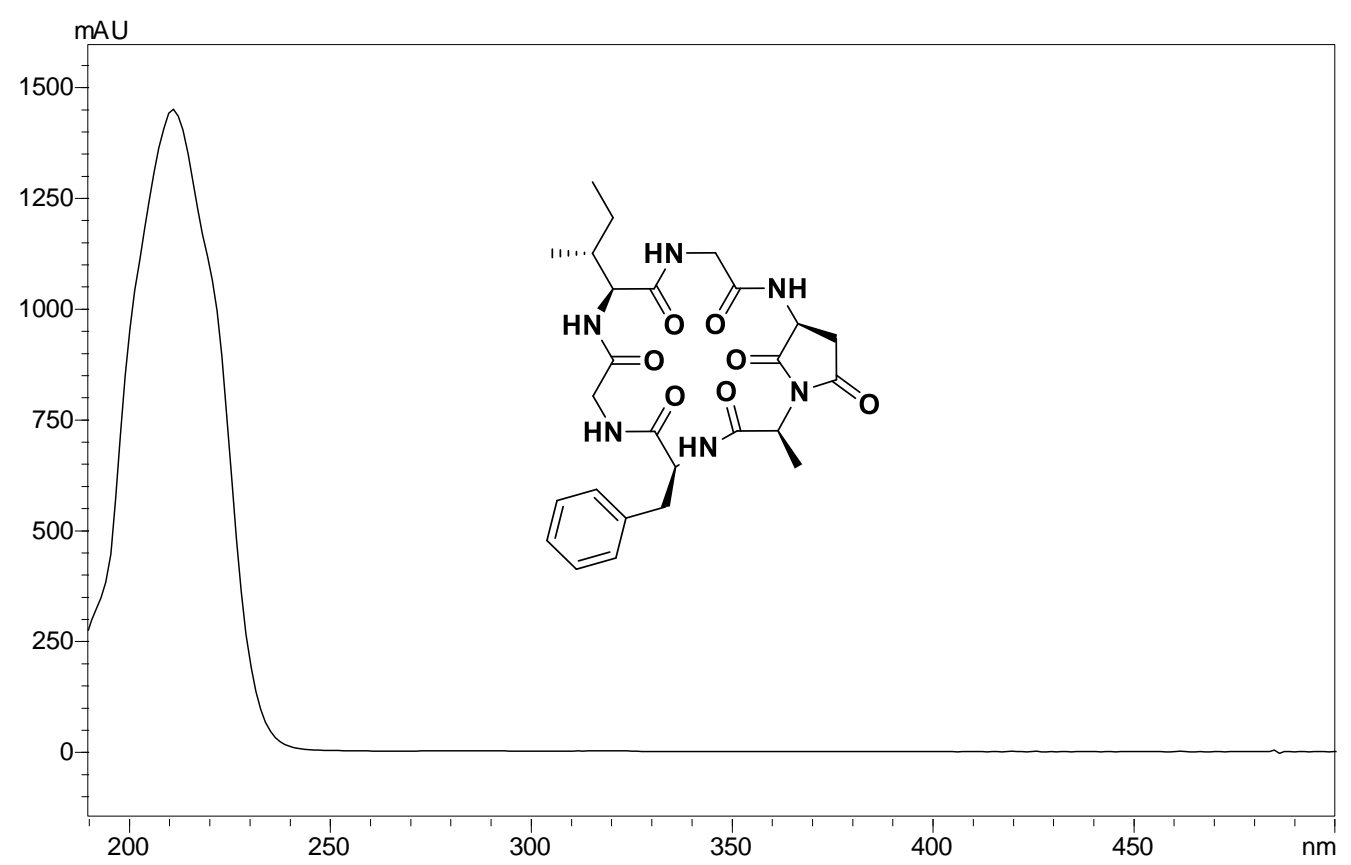

Figure S10. UV (DMSO) Spectrum of compound 1

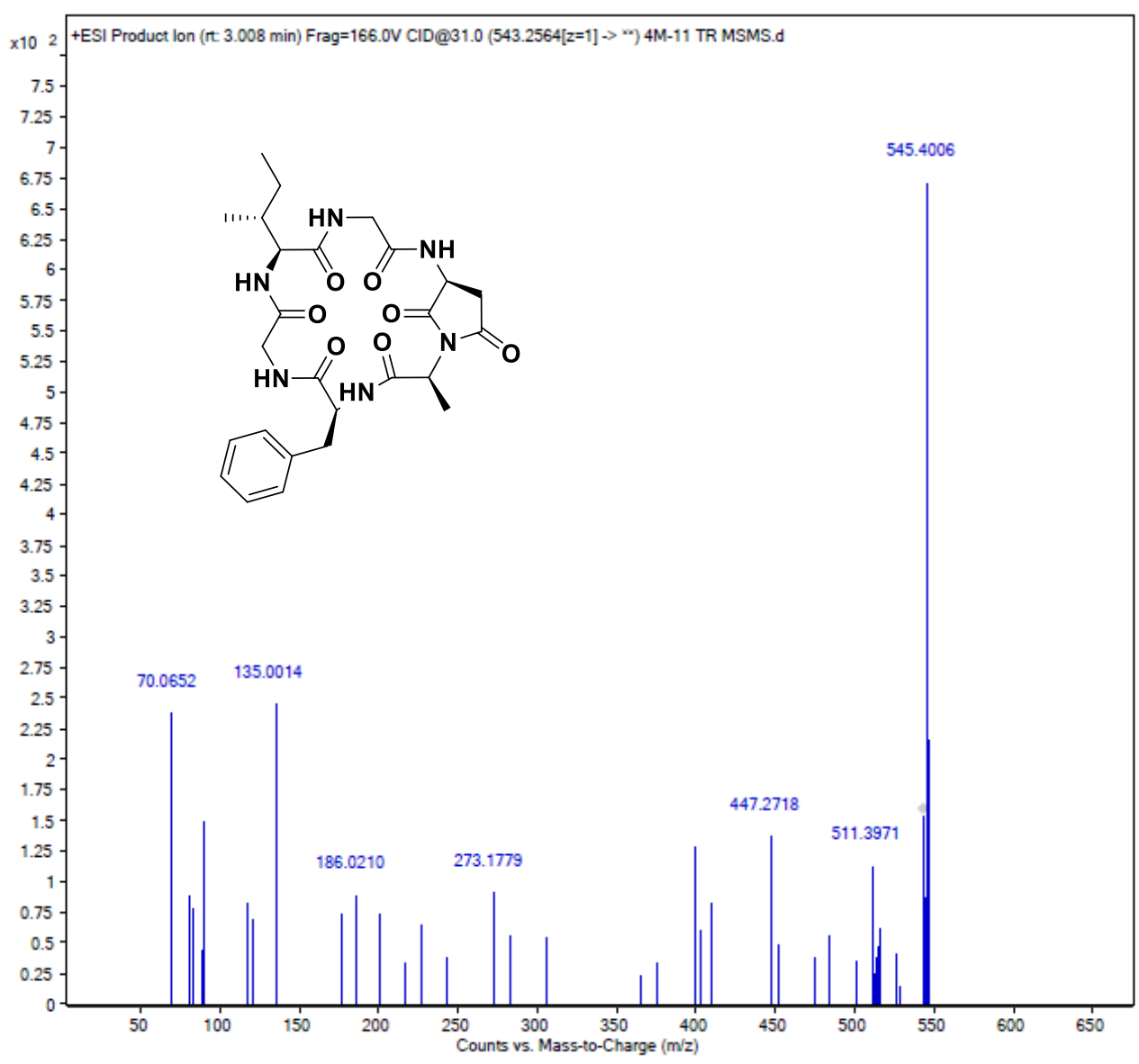

Figure S11. HRESIMS/MS Spectrum of compound 1 


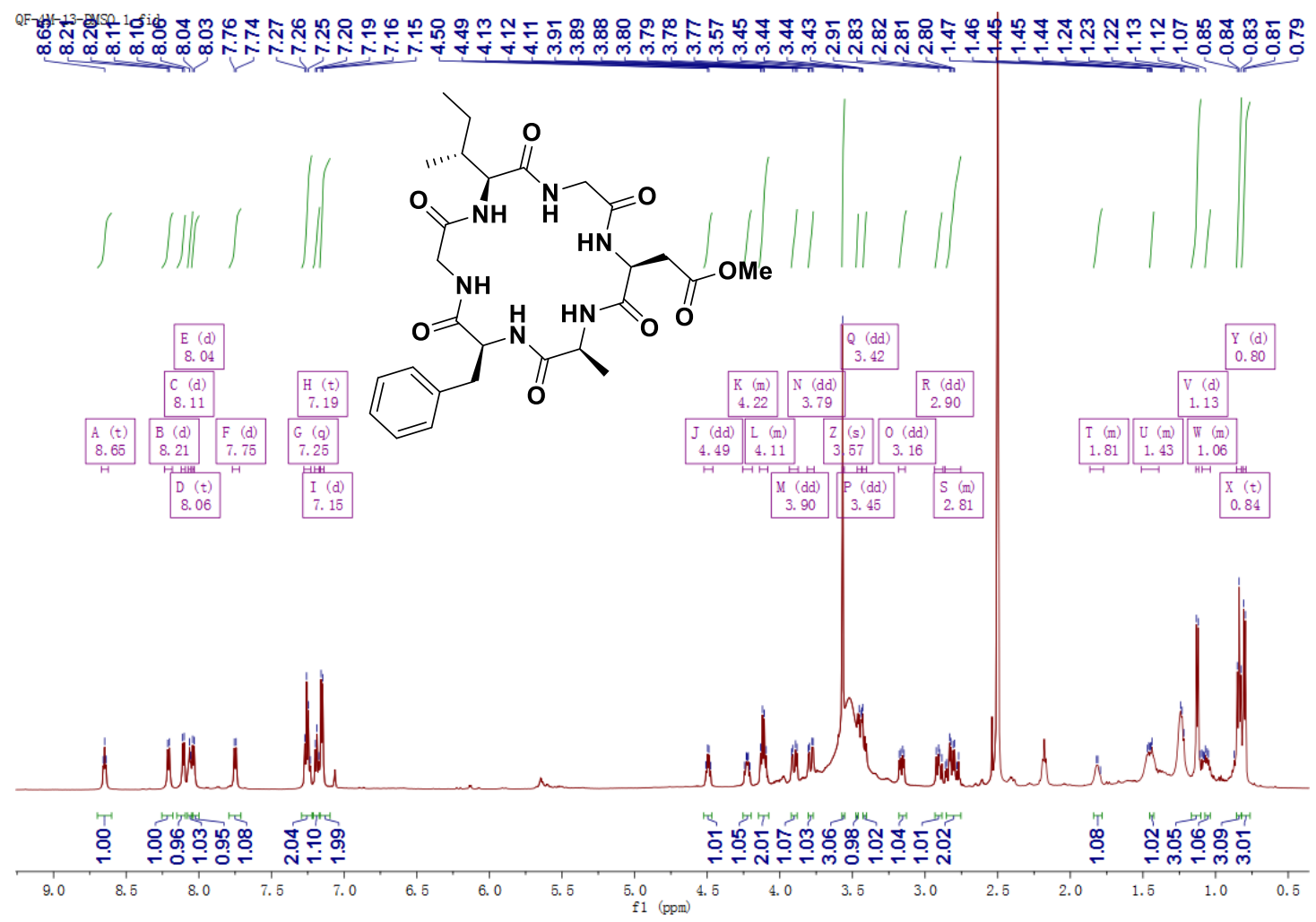

Figure S12. ${ }^{1} \mathrm{H}$ NMR spectrum of compound 2 in DMSO at $600 \mathrm{MHz}$

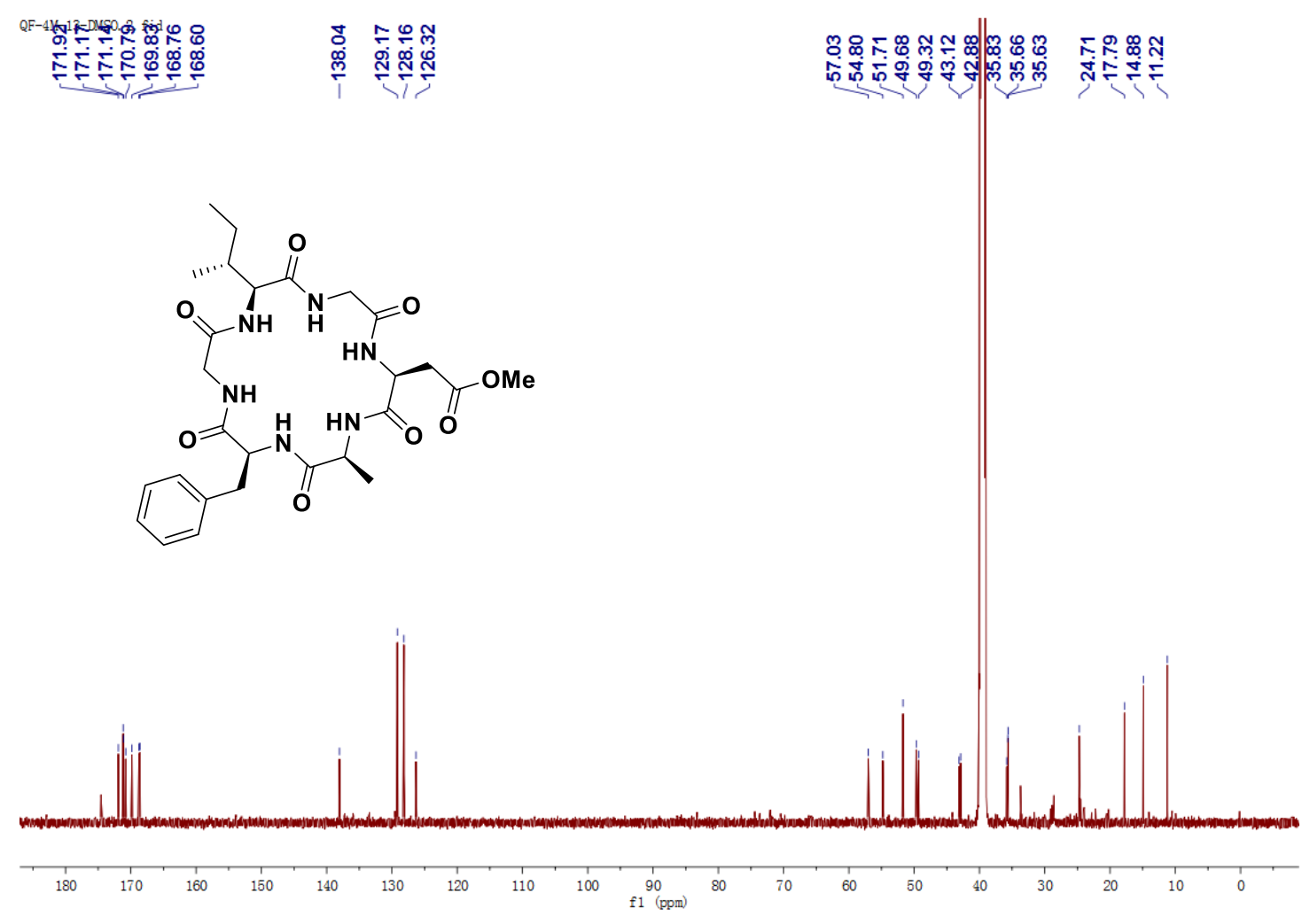

Figure S13. ${ }^{13} \mathrm{C}\left\{{ }^{1} \mathrm{H}\right\}$ NMR spectrum of compound 2 in DMSO at $150 \mathrm{MHz}$ 


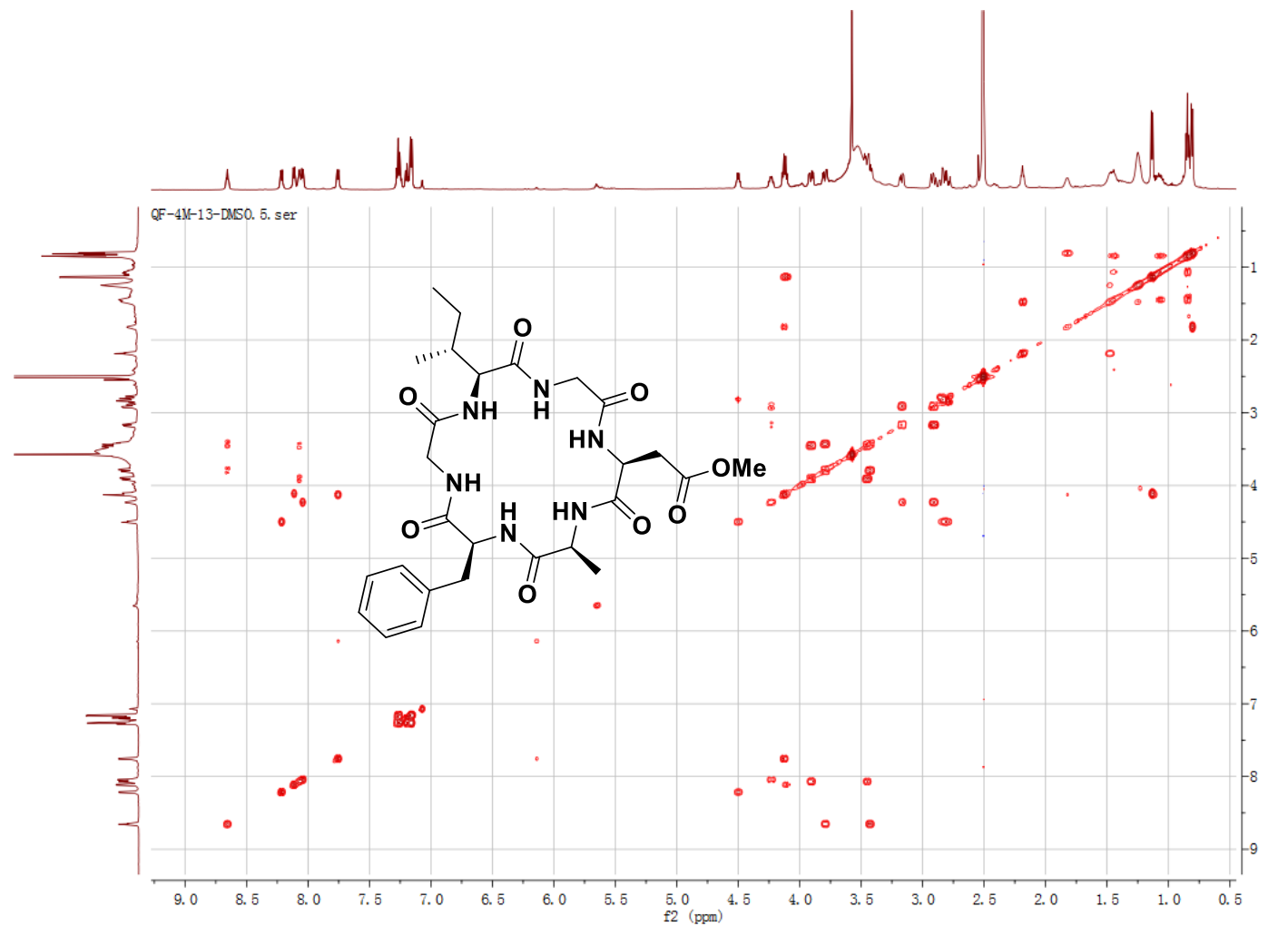

Figure S14. COSY spectrum of compound 2 in DMSO

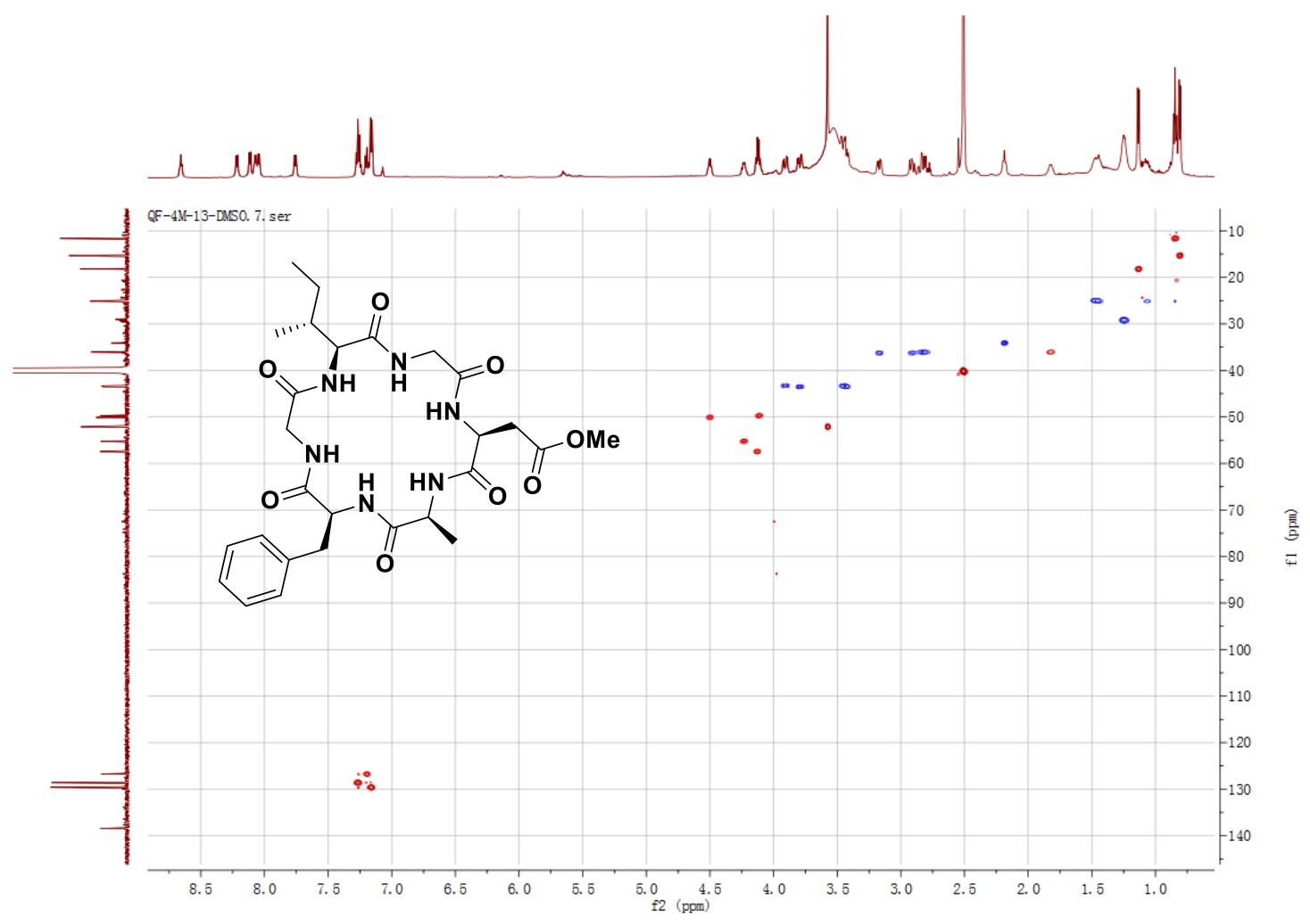

Figure S15. HSQC spectrum of compound 2 in DMSO 


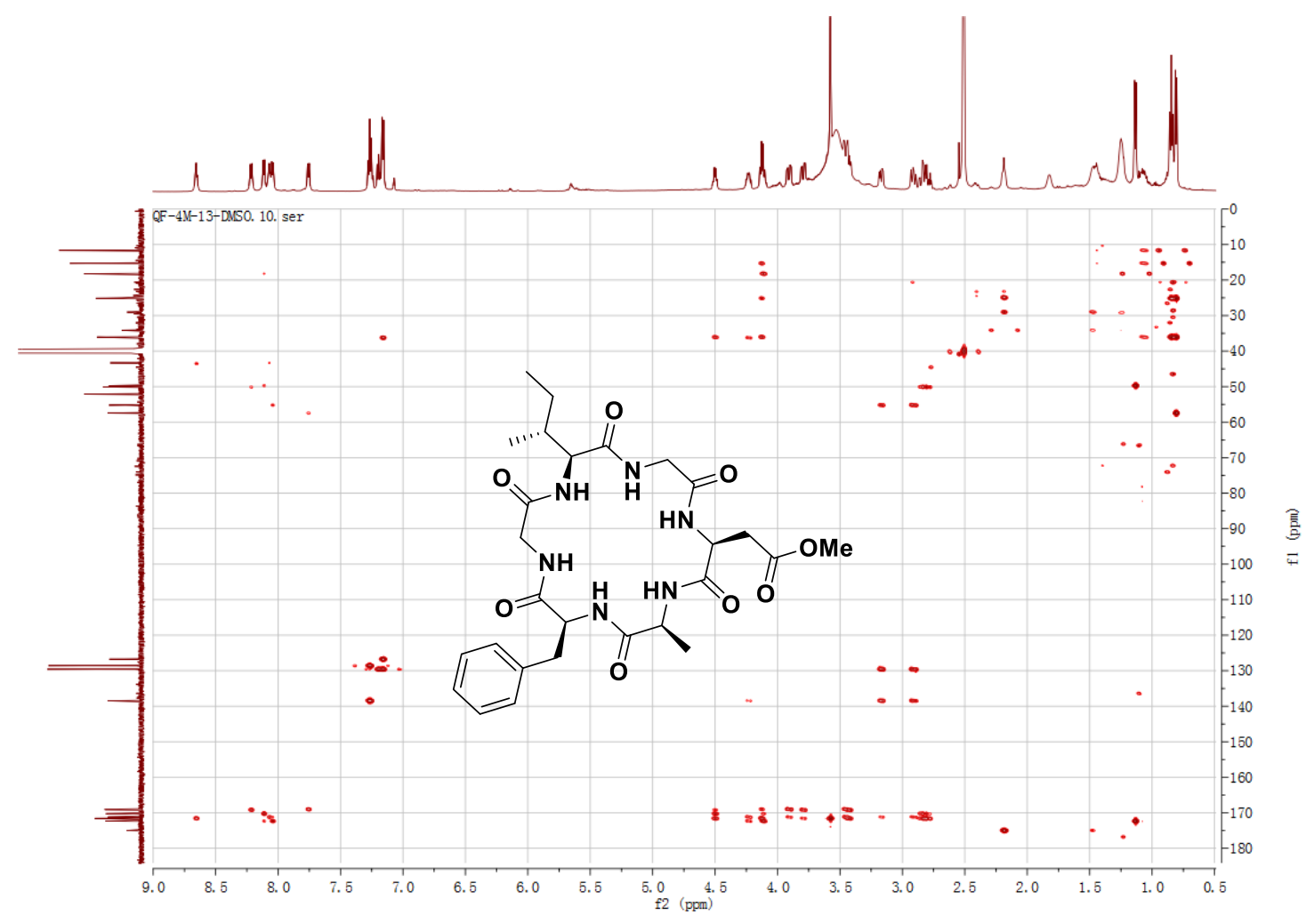

Figure S16. HMBC spectrum of compound 2 in DMSO

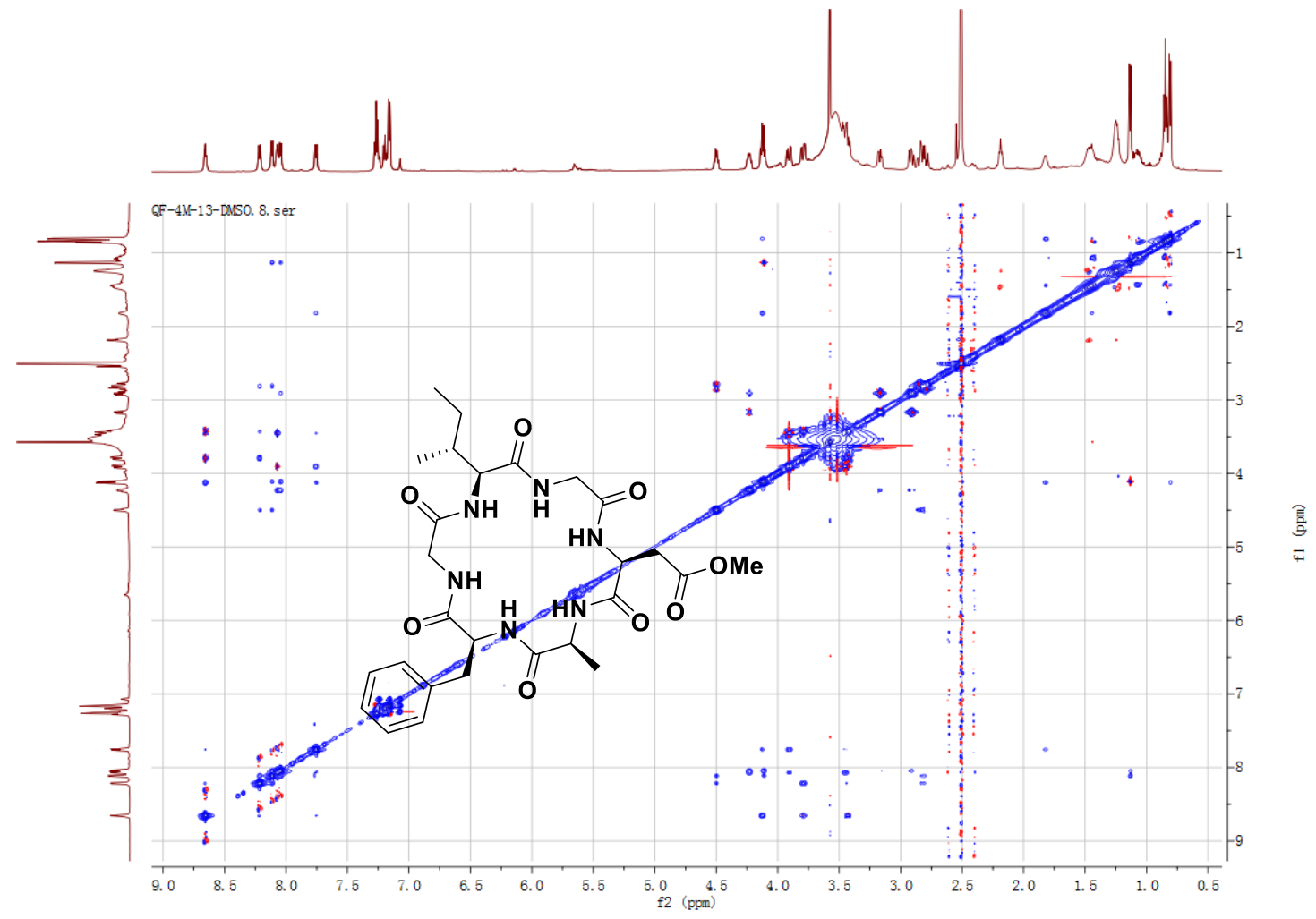

Figure S17. NOESY spectrum of compound 2 in DMSO 


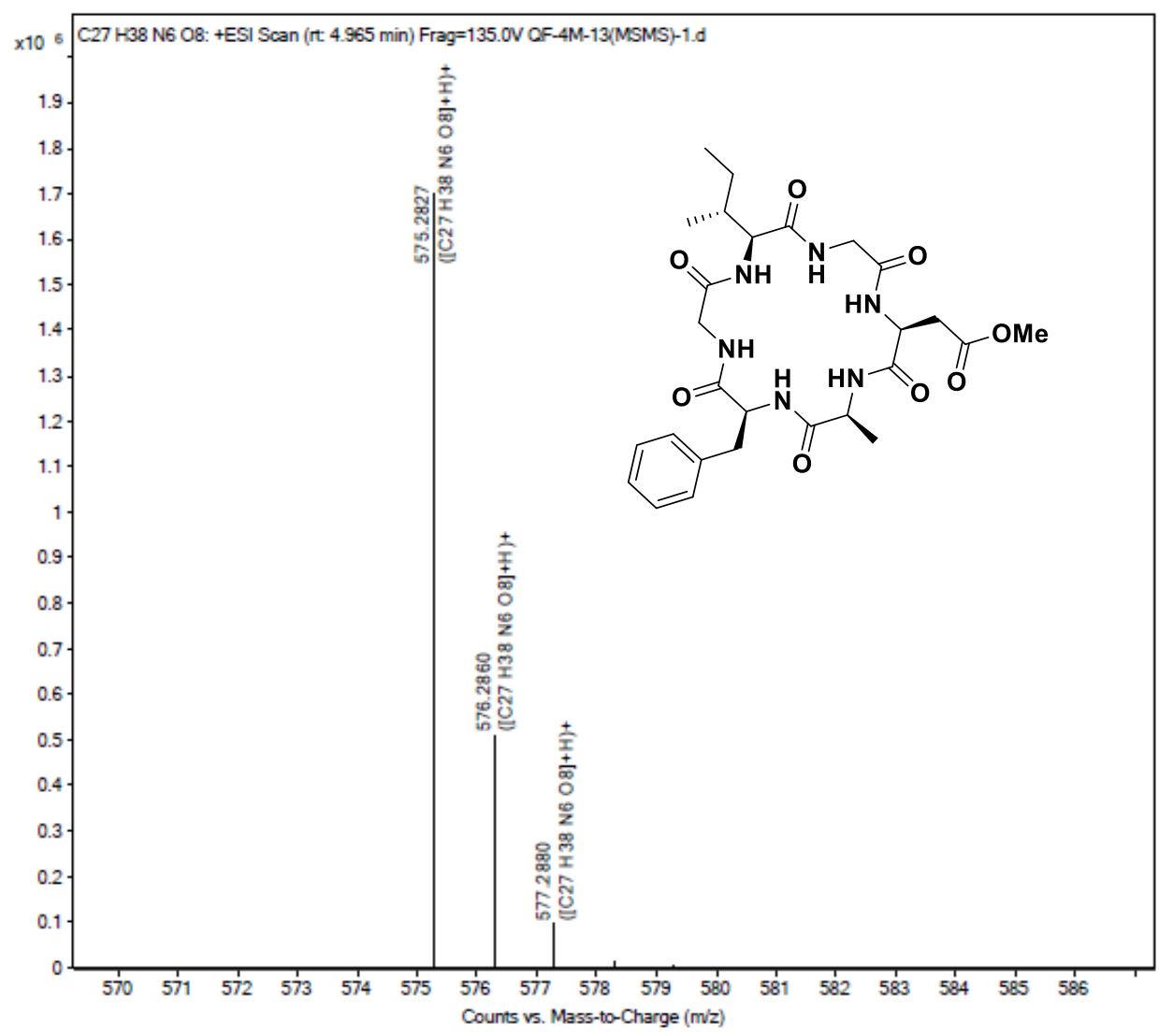

Figure S18. (+) HRESIMS Spectrum of compound 2

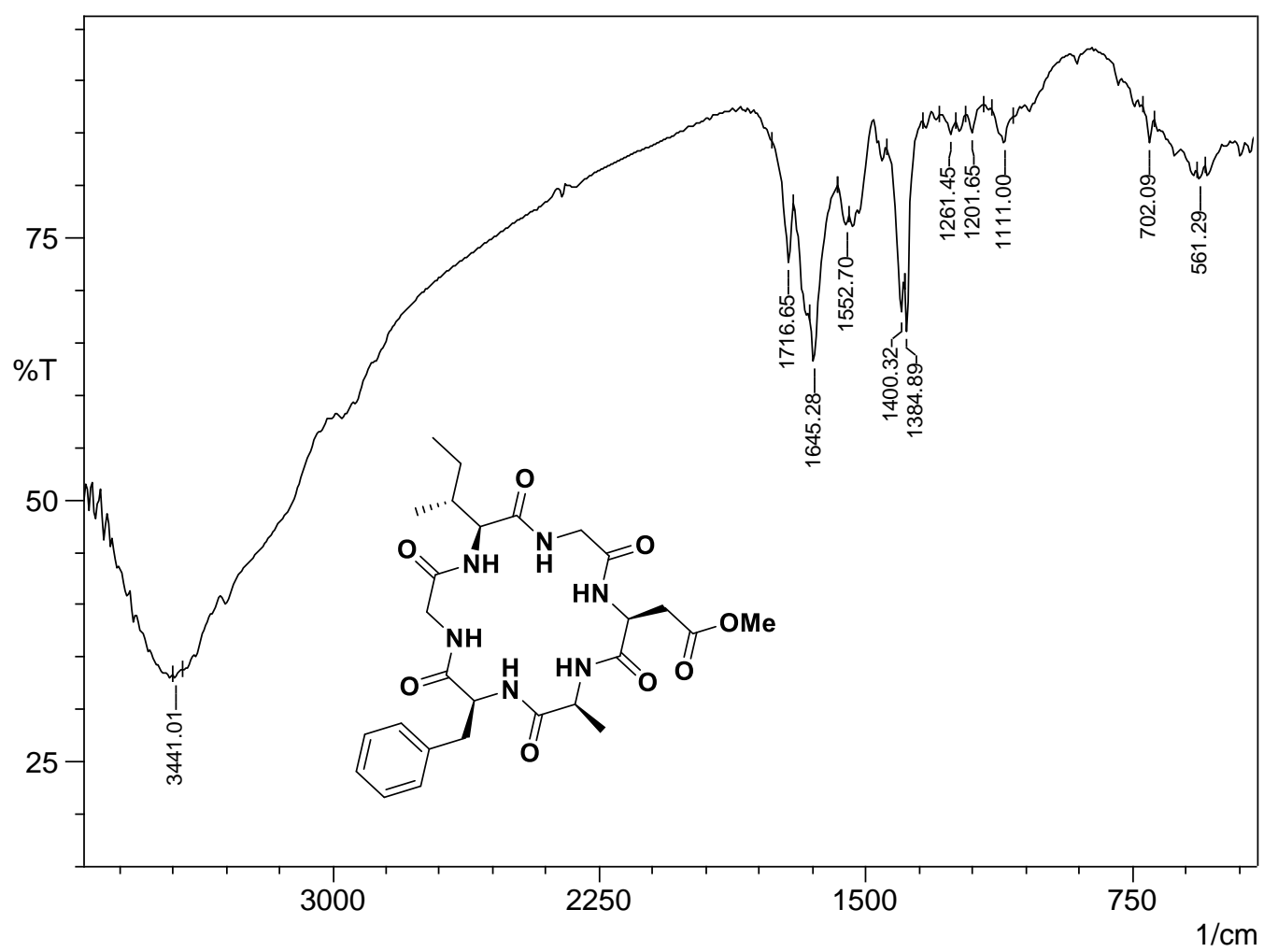

Figure S19. IR (KBr) Spectrum of compound 2 


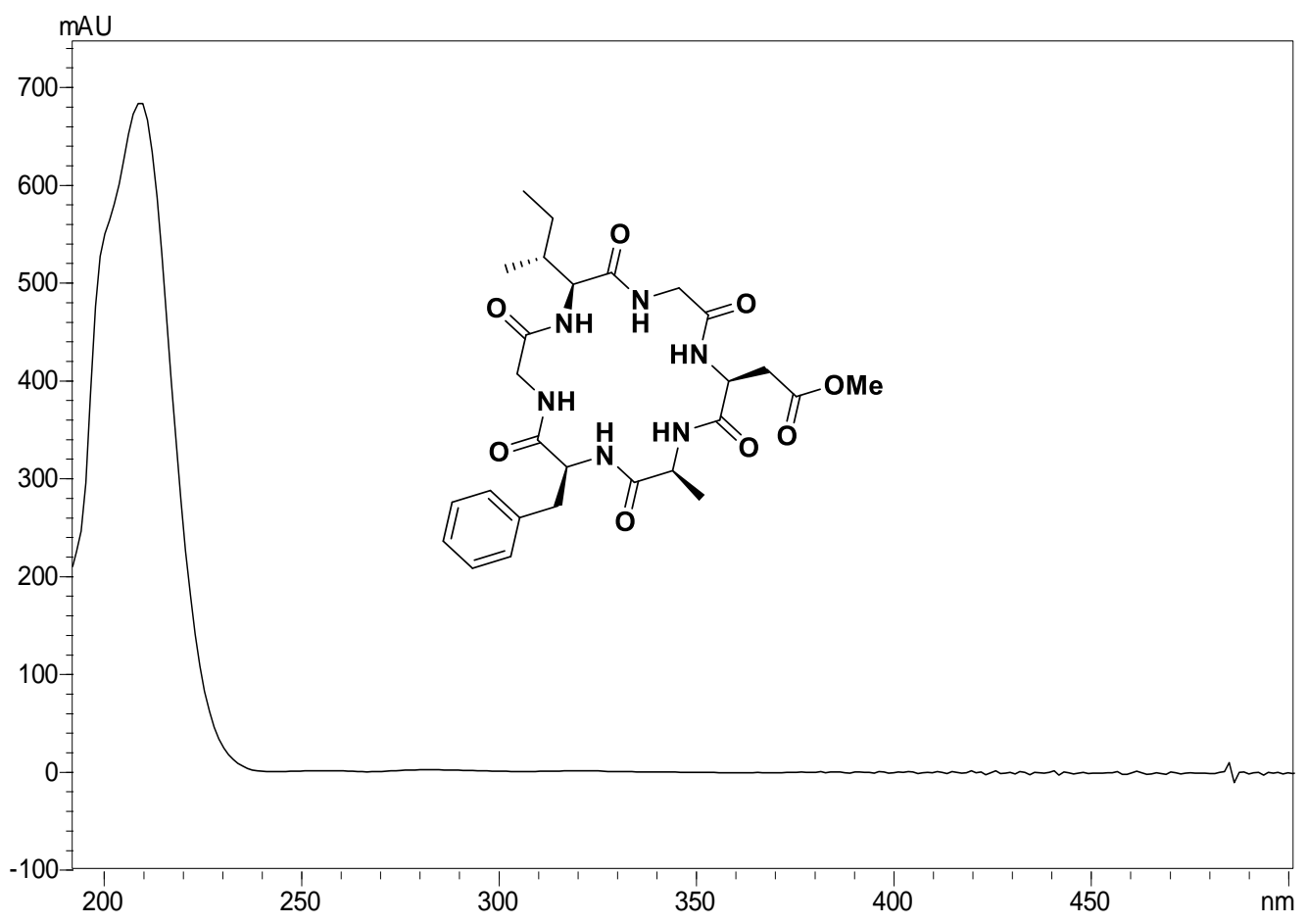

Figure S20. UV (DMSO) Spectrum of compound 2

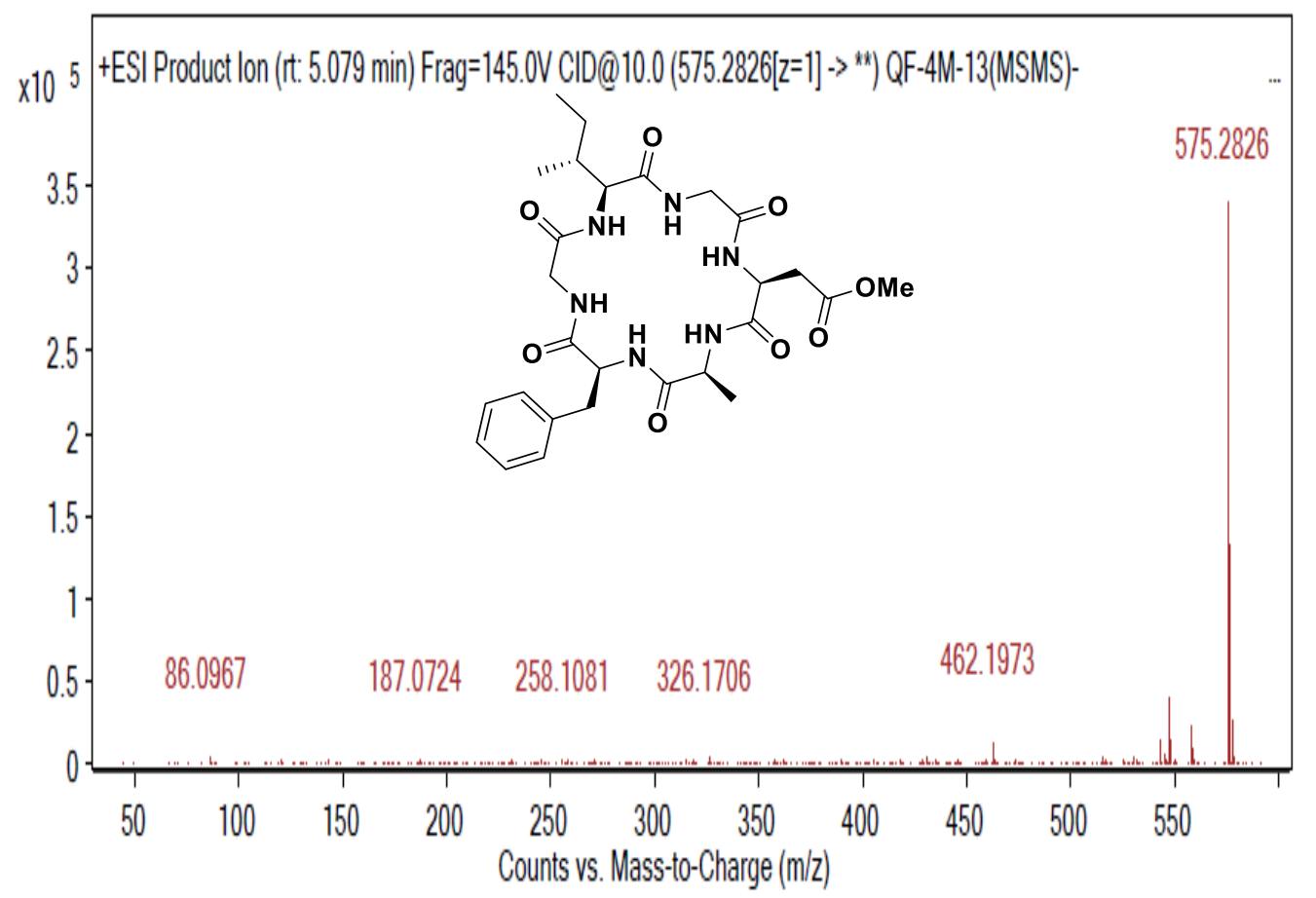

Figure S21. HRESIMS/MS Spectrum of compound 2 


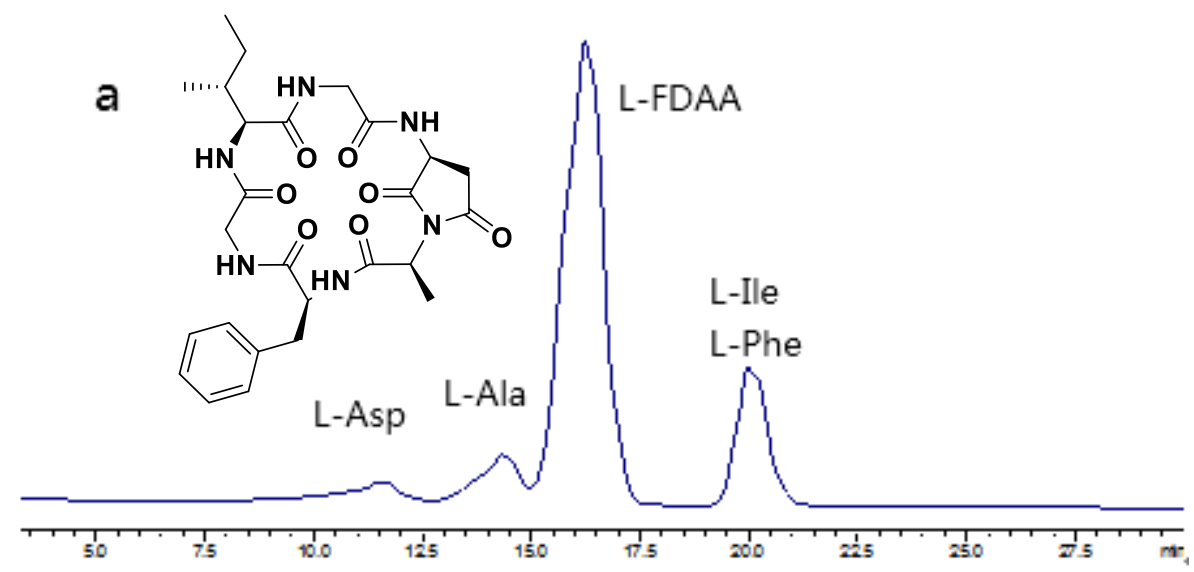

Figure S22. The HPLC analysis of L-FDAA derivatives of $\mathbf{1}$

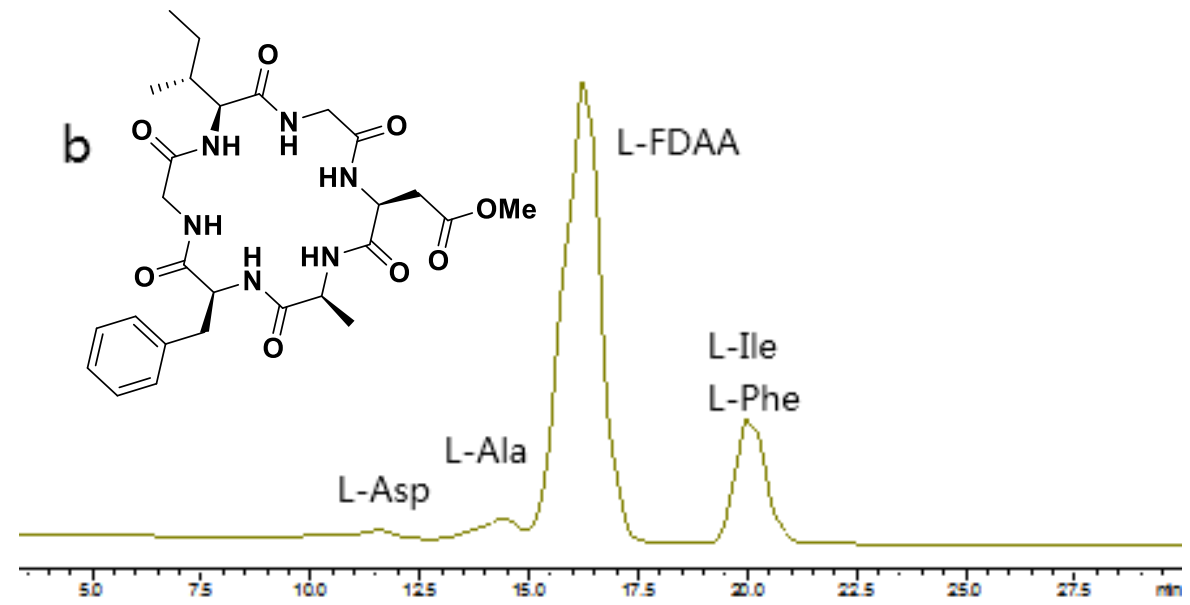

Figure S23. The HPLC analysis of L-FDAA derivatives of 2

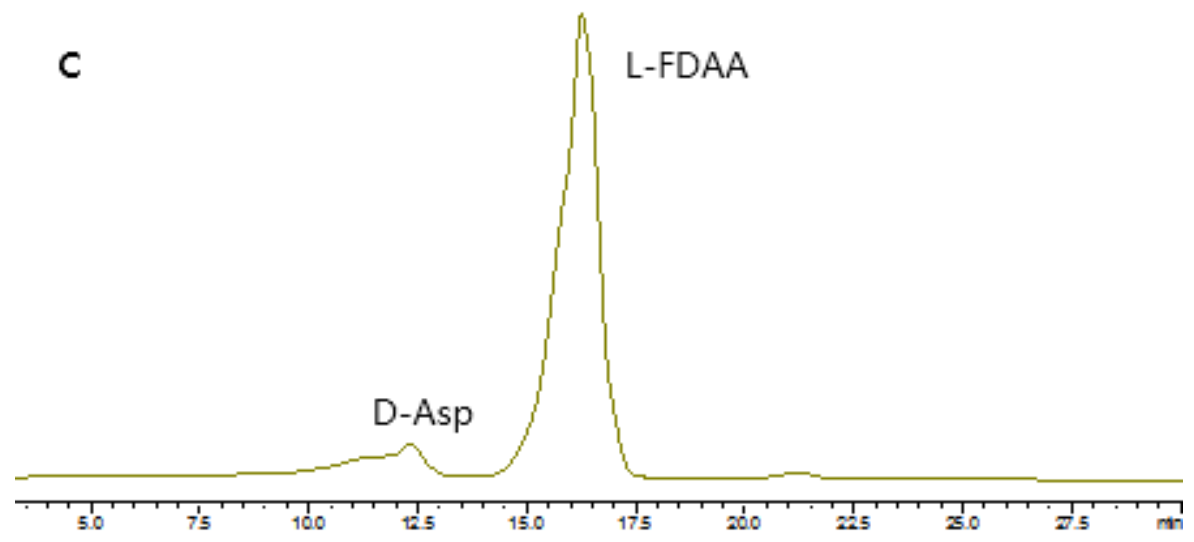



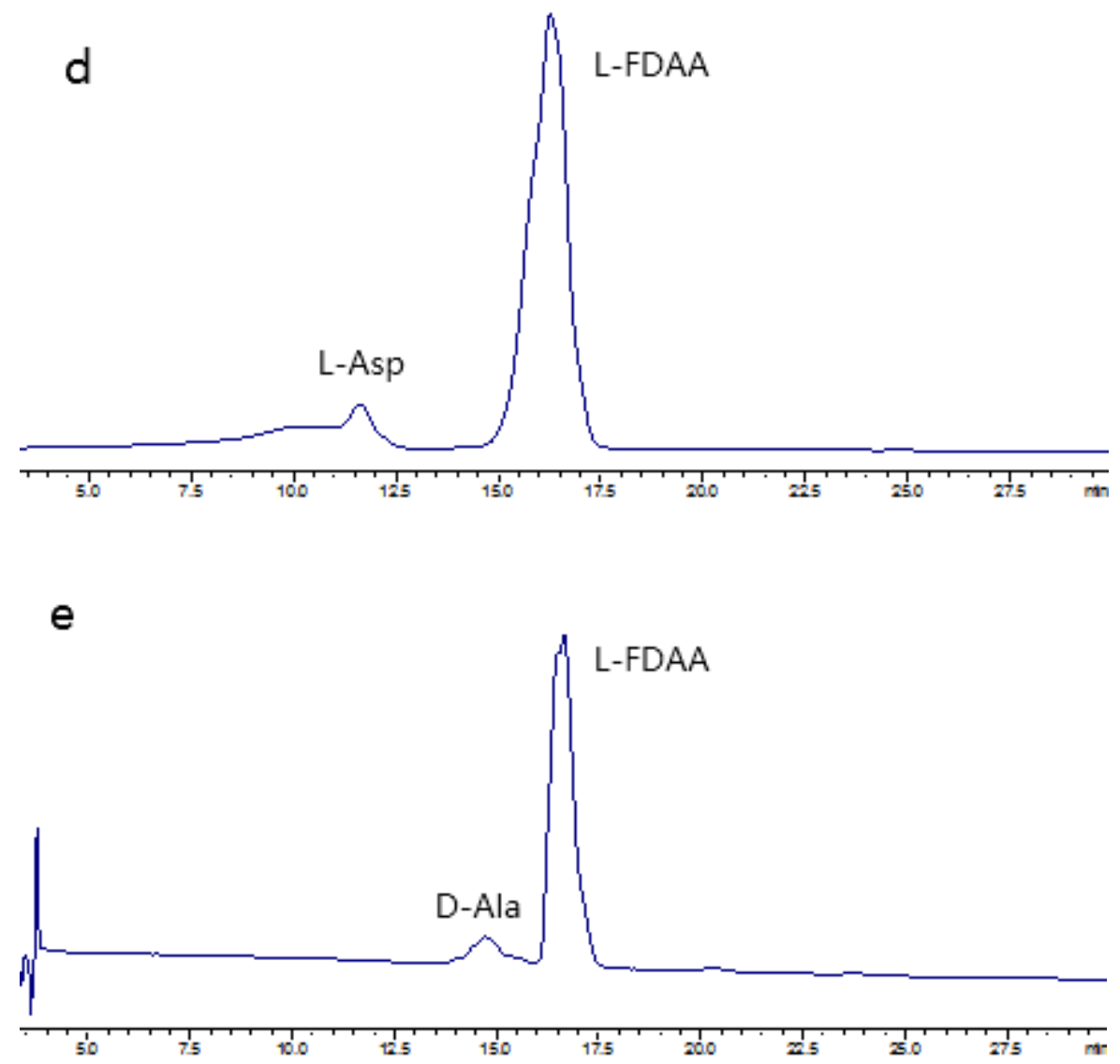

\section{f}
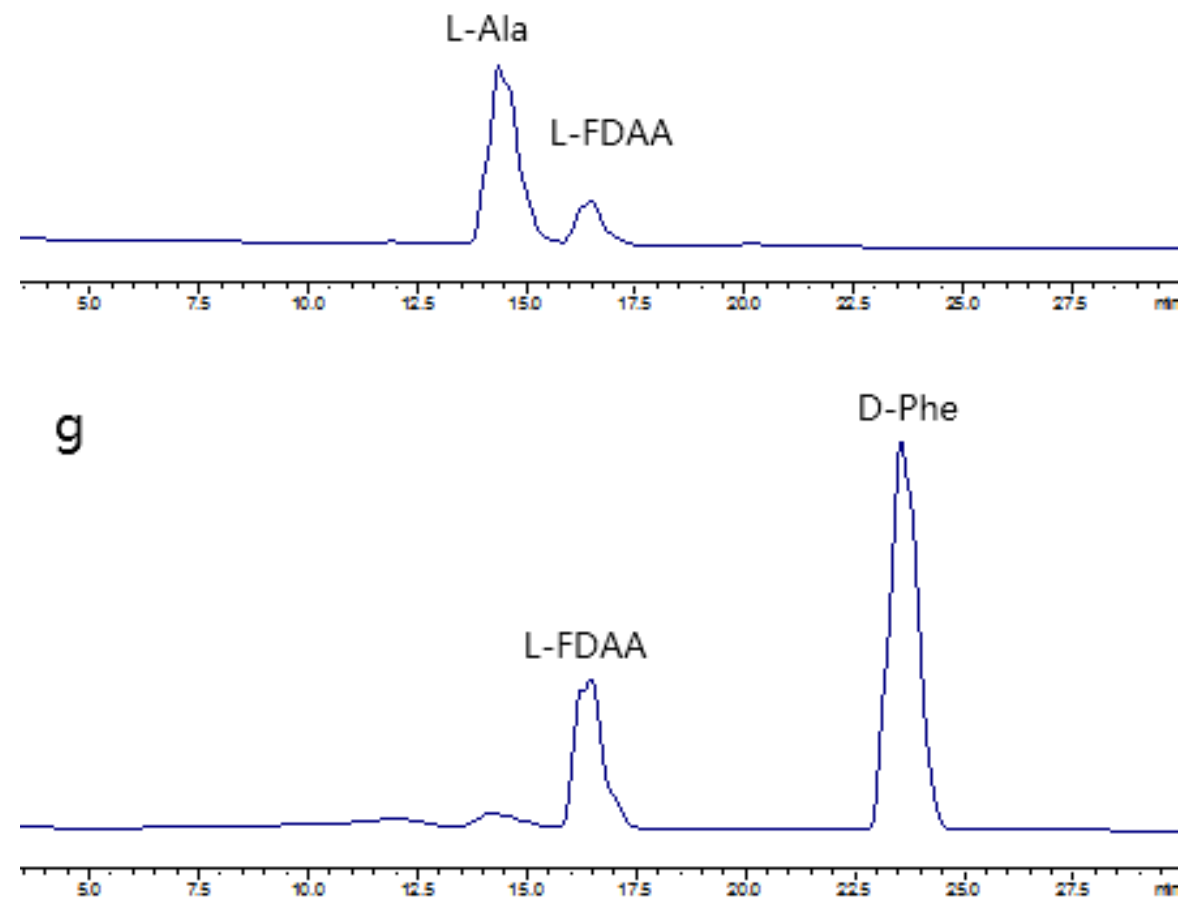

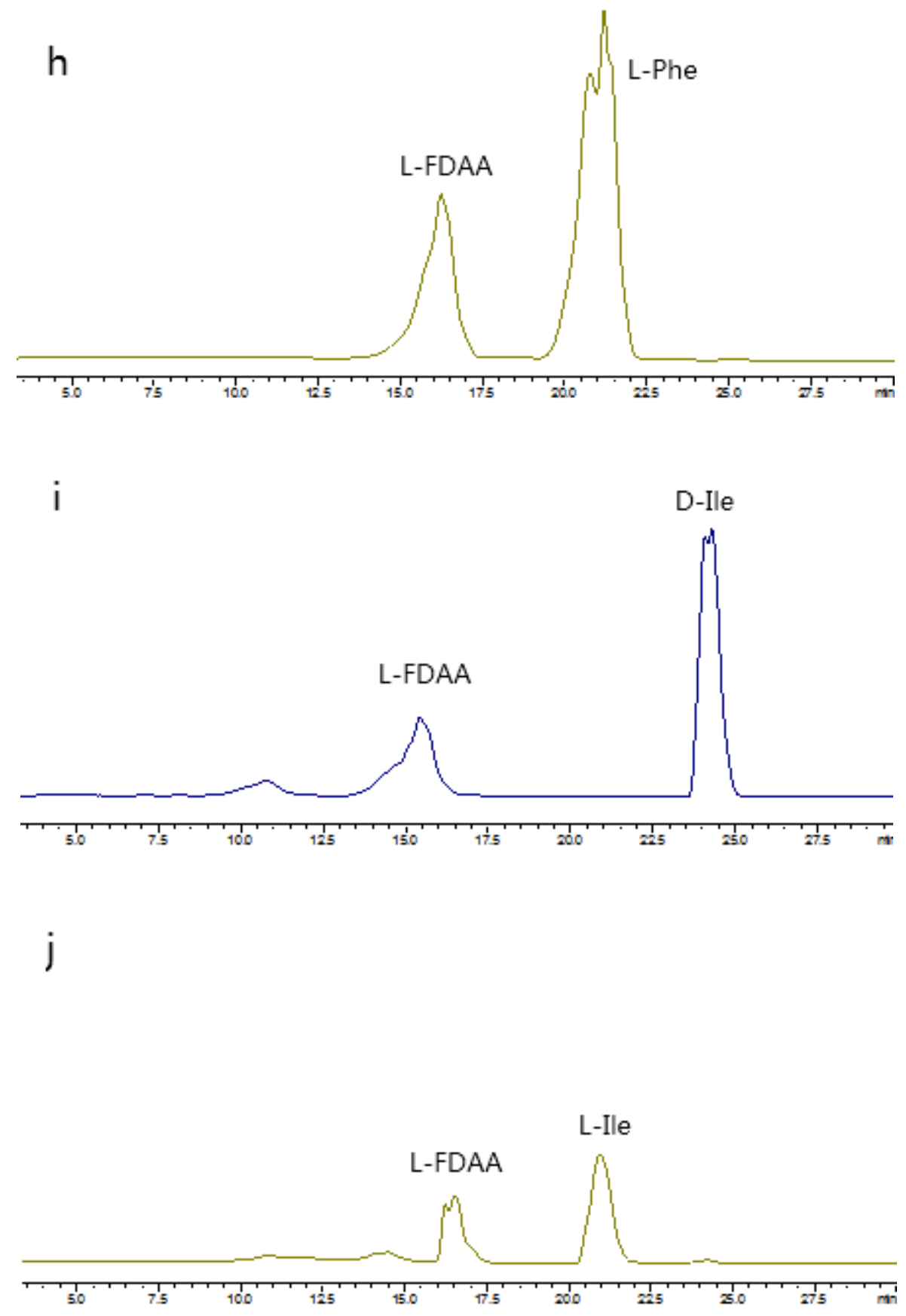

Figure S24. The HPLC analysis of L-FDAA derivatives of standard amino acids.(c) L-Asp, (d) D-Asp, (e) L-Ala, (f) D-Ala, (g) L-Ile, (h) D-Ile, (i)L-Phe, (j) D-Phe 


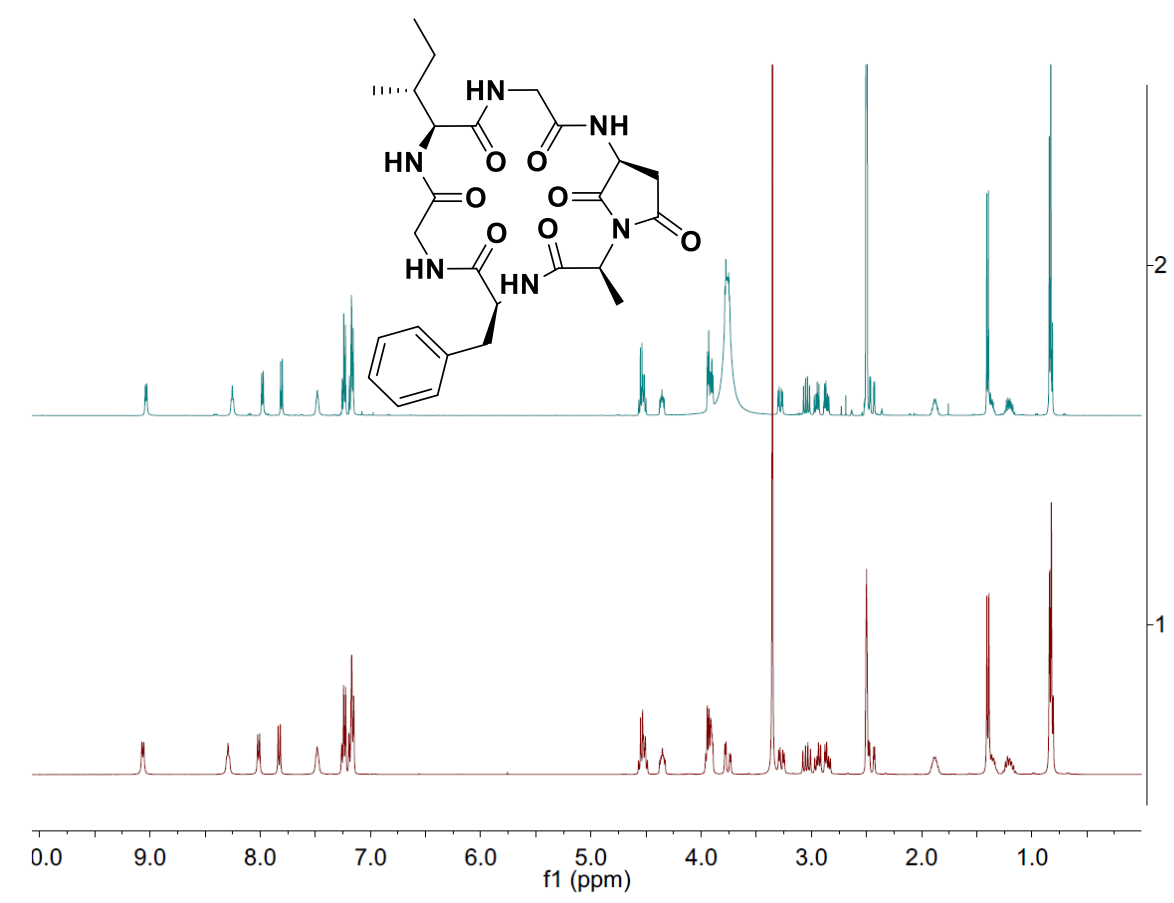

Figure S25. ${ }^{1} \mathrm{H}$ NMR comparison of natural Nitidumpeptin A (below) and synthetic one (above)

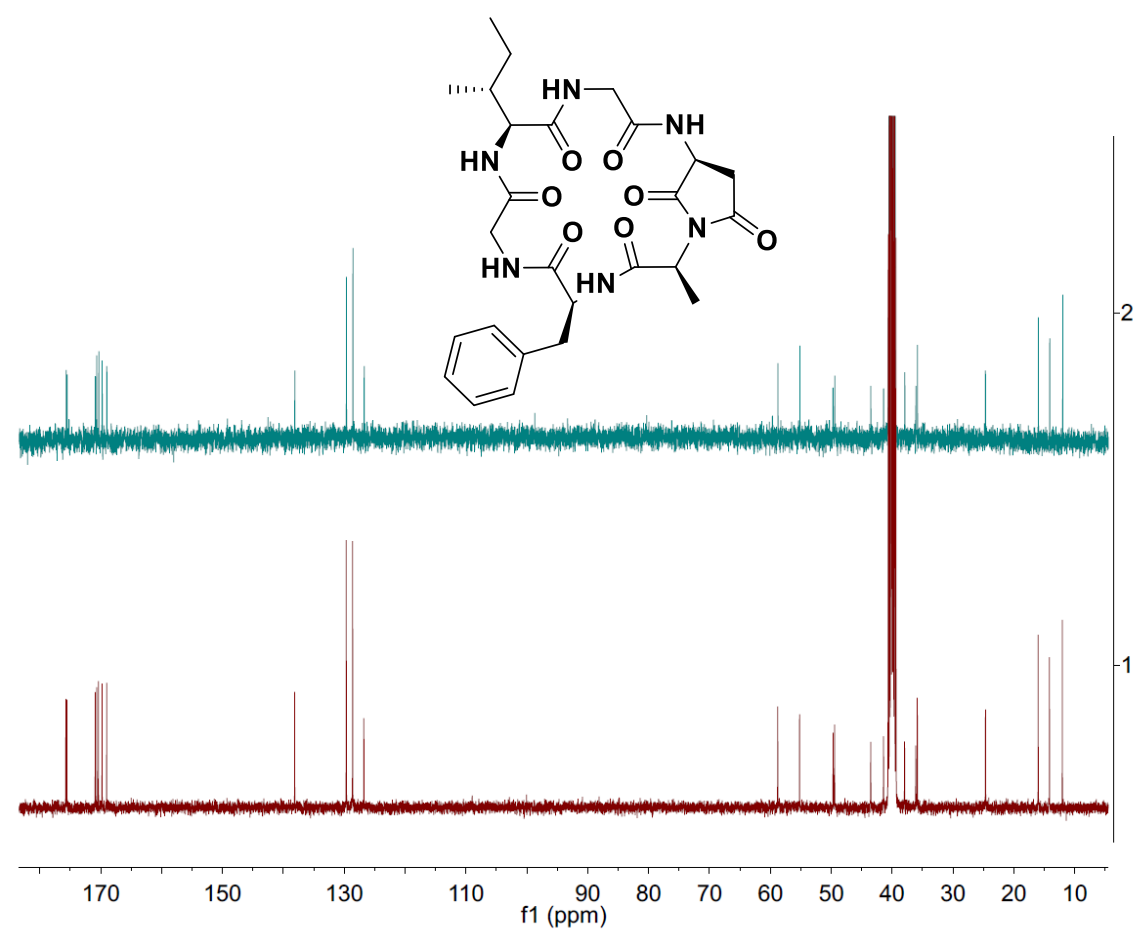

Figure S26. ${ }^{13} \mathrm{C}\left\{{ }^{1} \mathrm{H}\right\}$ NMR comparison of natural Nitidumpeptin A (below) and synthetic one (above) 


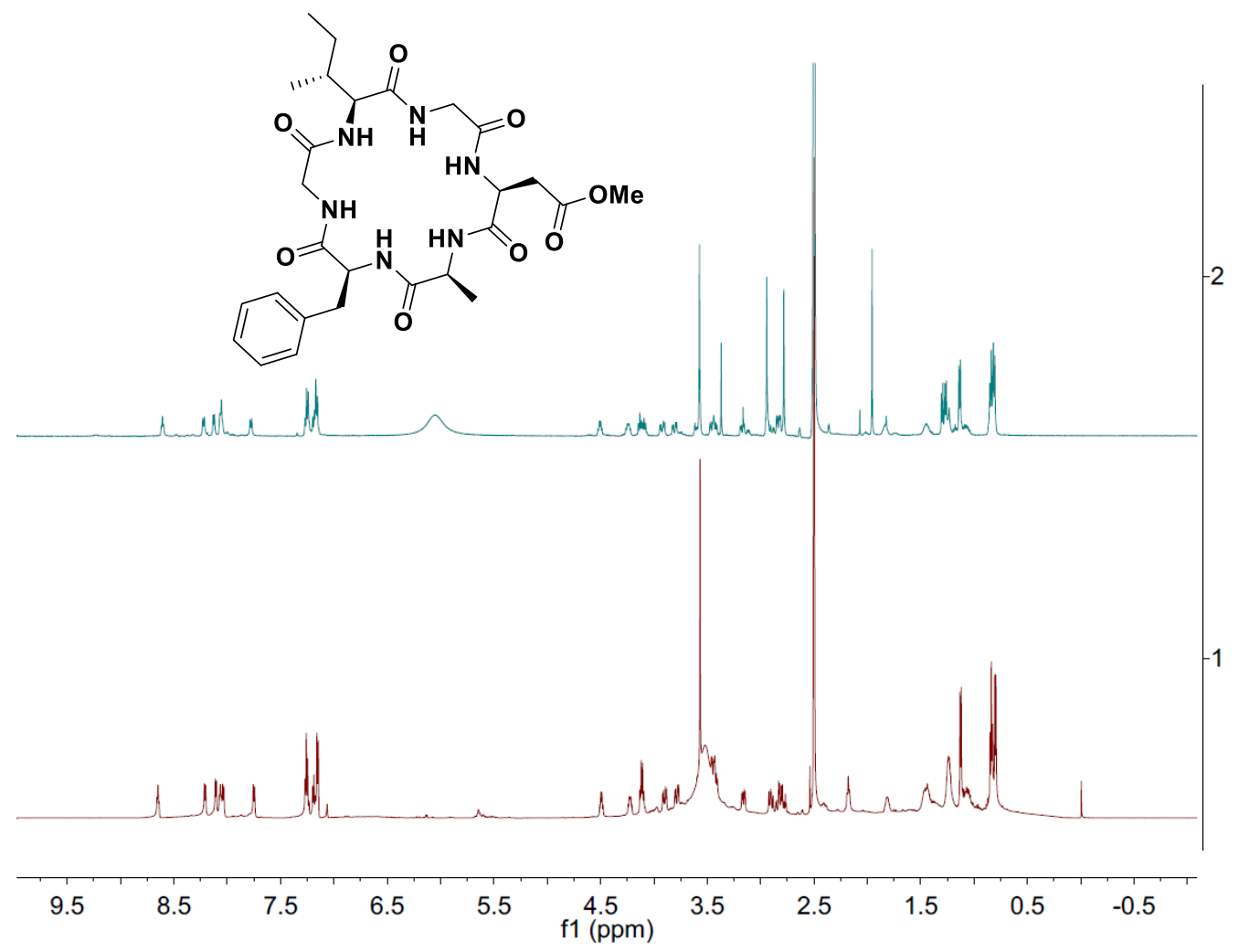

Figure S27. ${ }^{1}$ H NMR comparison of natural Nitidumpeptin B (below) and synthetic one (above)

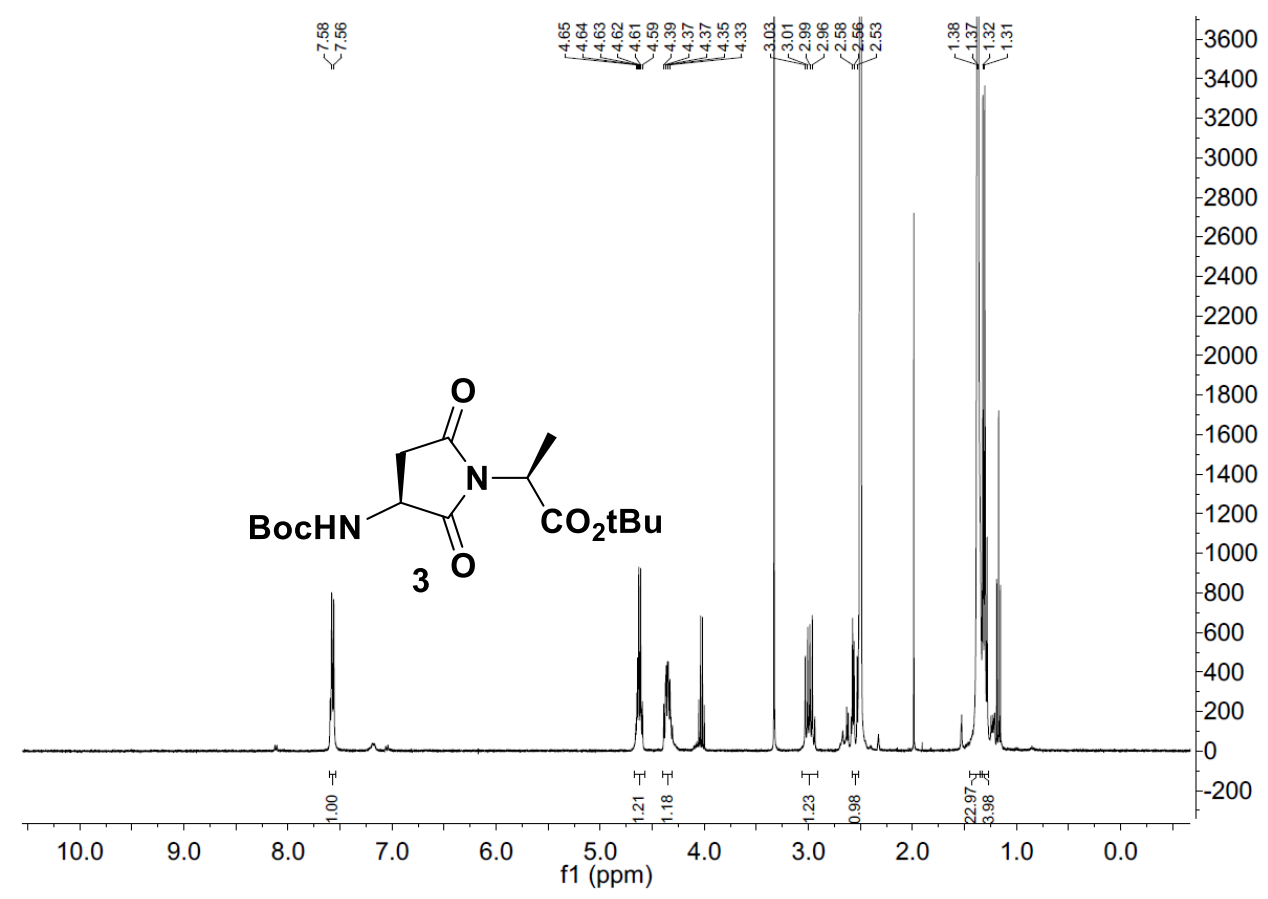

Figure S28. ${ }^{1} \mathrm{H}$ NMR spectrum of compound 3 in DMSO at $400 \mathrm{MHz}$ 


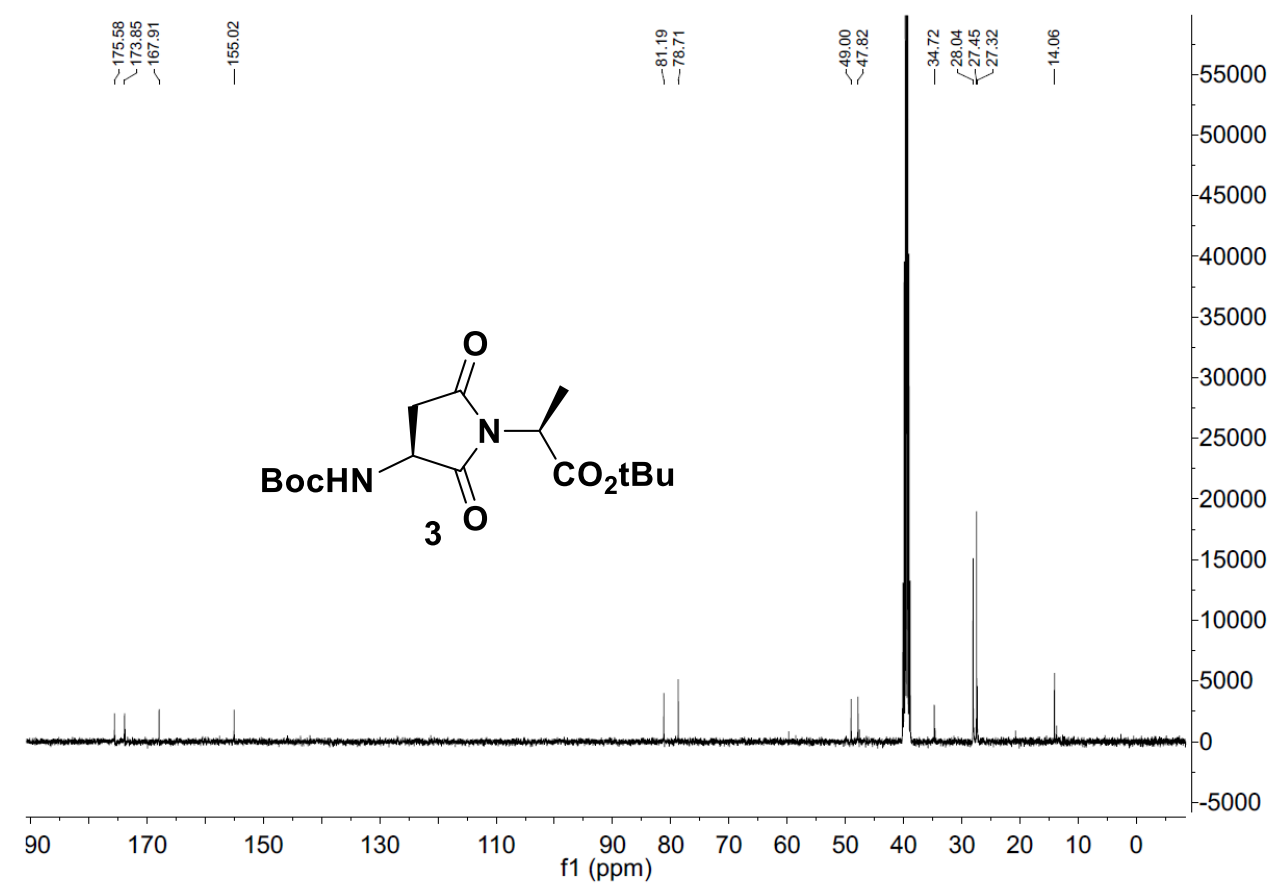

Figure S29. ${ }^{13} \mathrm{C}\left\{{ }^{1} \mathrm{H}\right\}$ NMR spectrum of compound 3 in DMSO at $100 \mathrm{MHz}$ IR

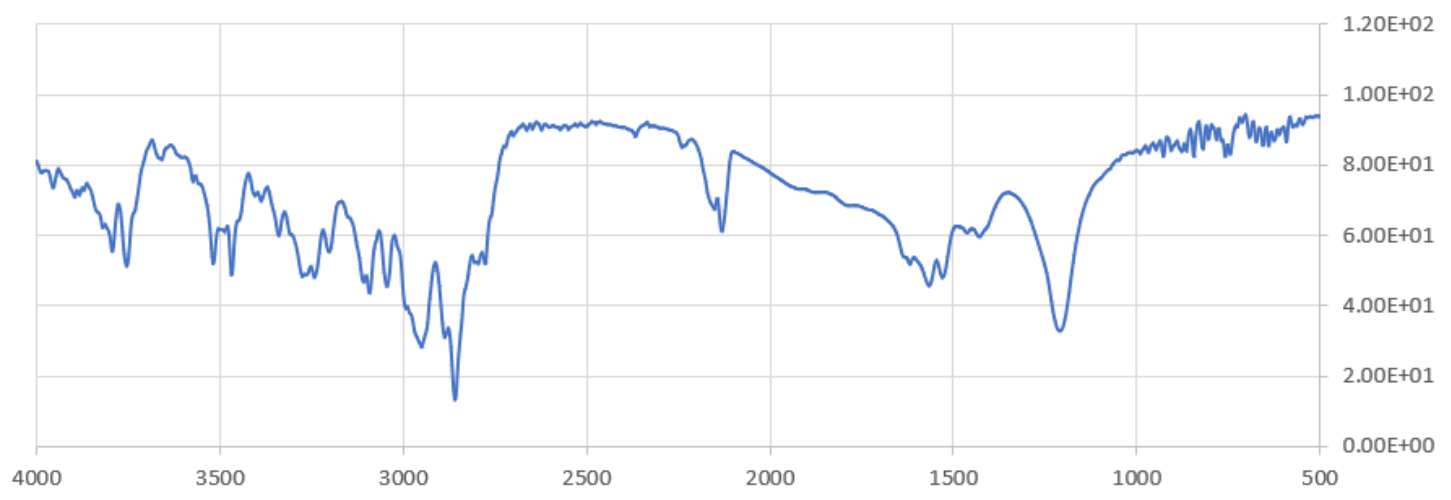

Figure S30. IR (KBr) Spectrum of compound 3 
<smiles>CC(C)OC(C)N1C(=O)CC(N)C1=O</smiles>
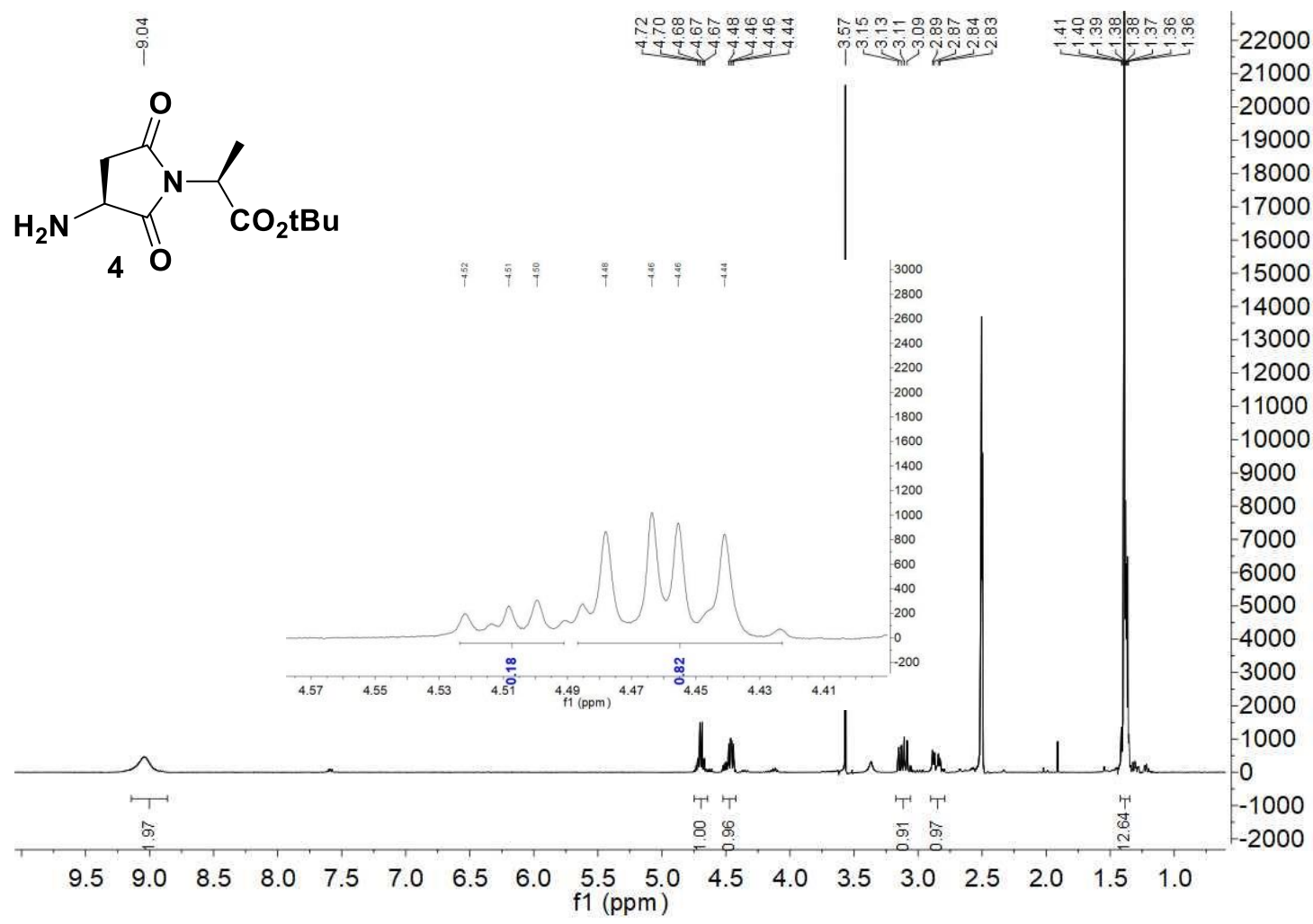

Figure S31. ${ }^{1} \mathrm{H}$ NMR spectrum of compound 4 in DMSO at $400 \mathrm{MHz}$

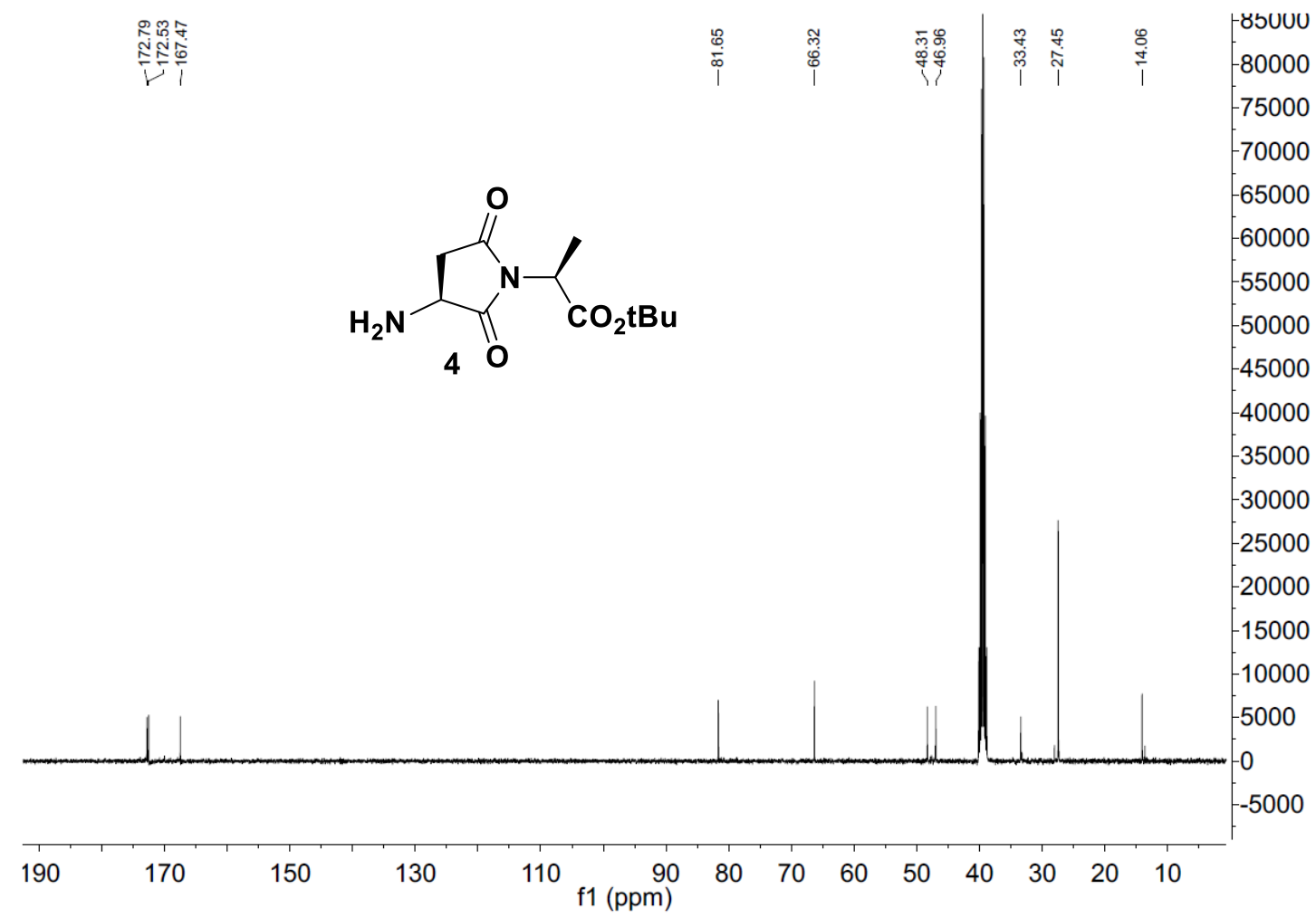

Figure S32. ${ }^{13} \mathrm{C}\left\{{ }^{1} \mathrm{H}\right\}$ NMR spectrum of compound 4 in DMSO at $100 \mathrm{MHz}$ 
IR Spectral

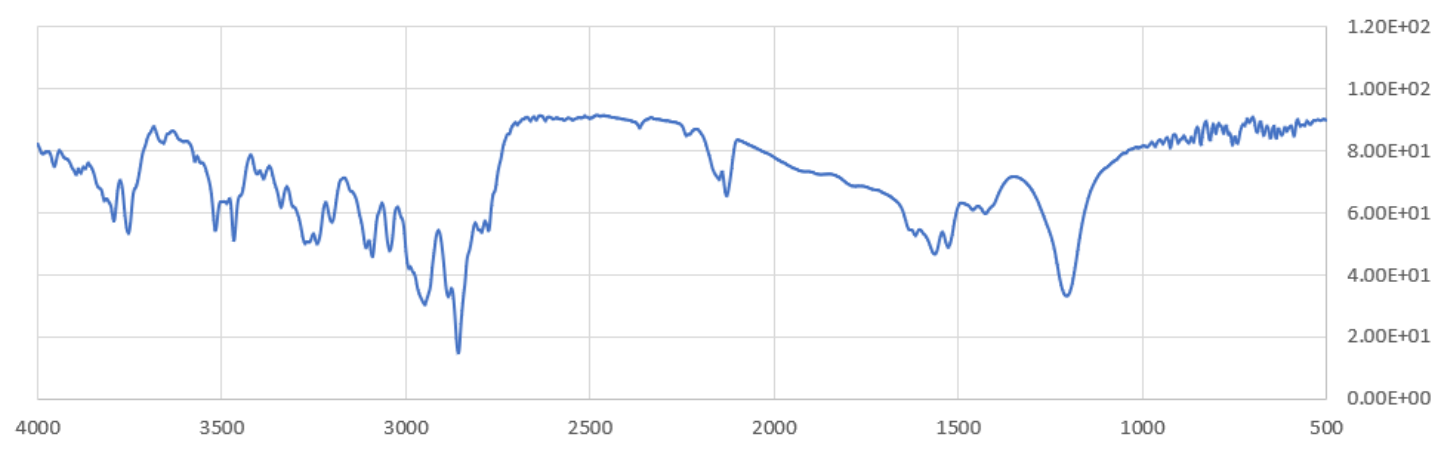

Figure S33. IR (KBr) Spectrum of compound 4

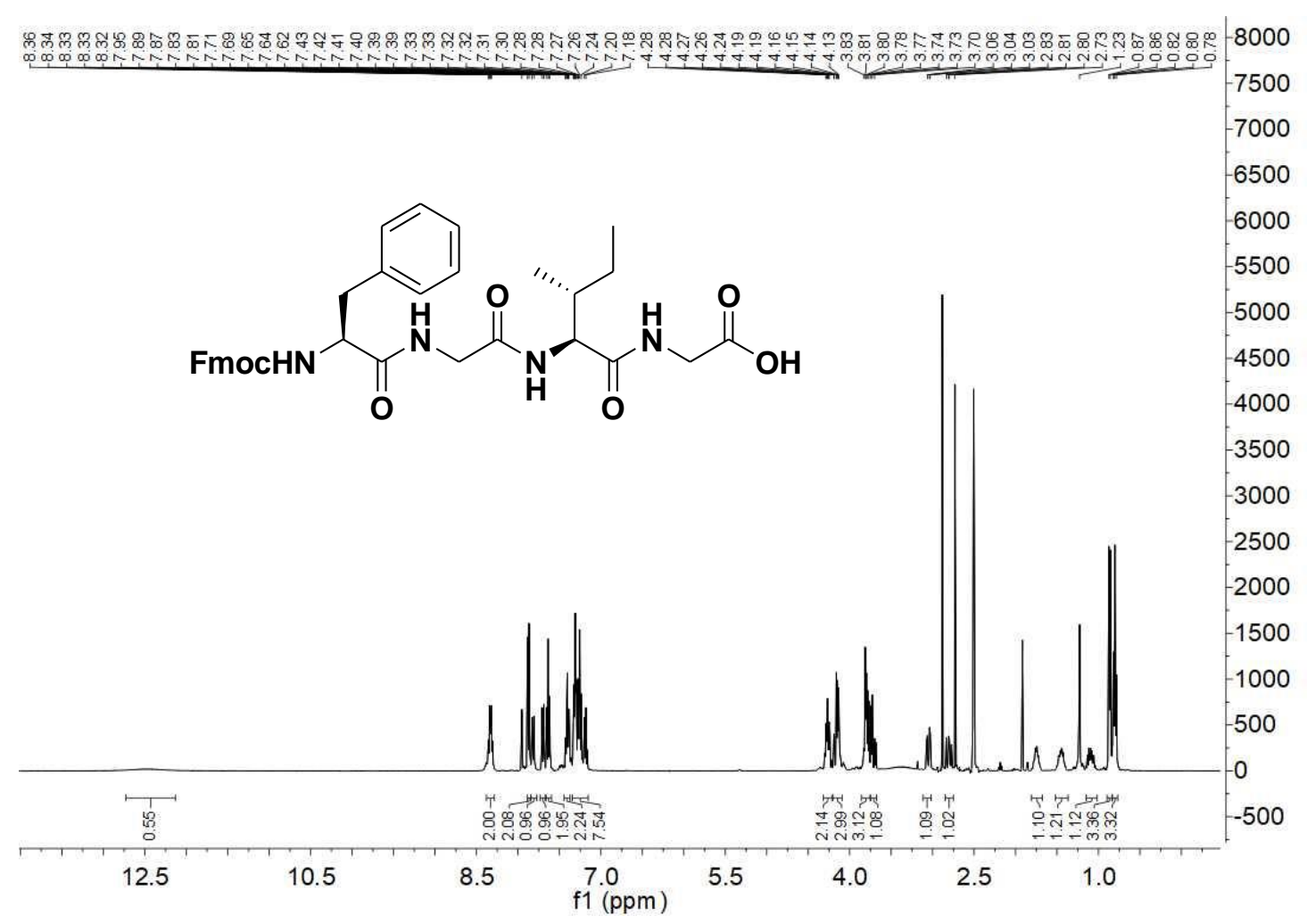

Figure S34. ${ }^{1} \mathrm{H}$ NMR spectrum of compound 6 in DMSO at $500 \mathrm{MHz}$ 


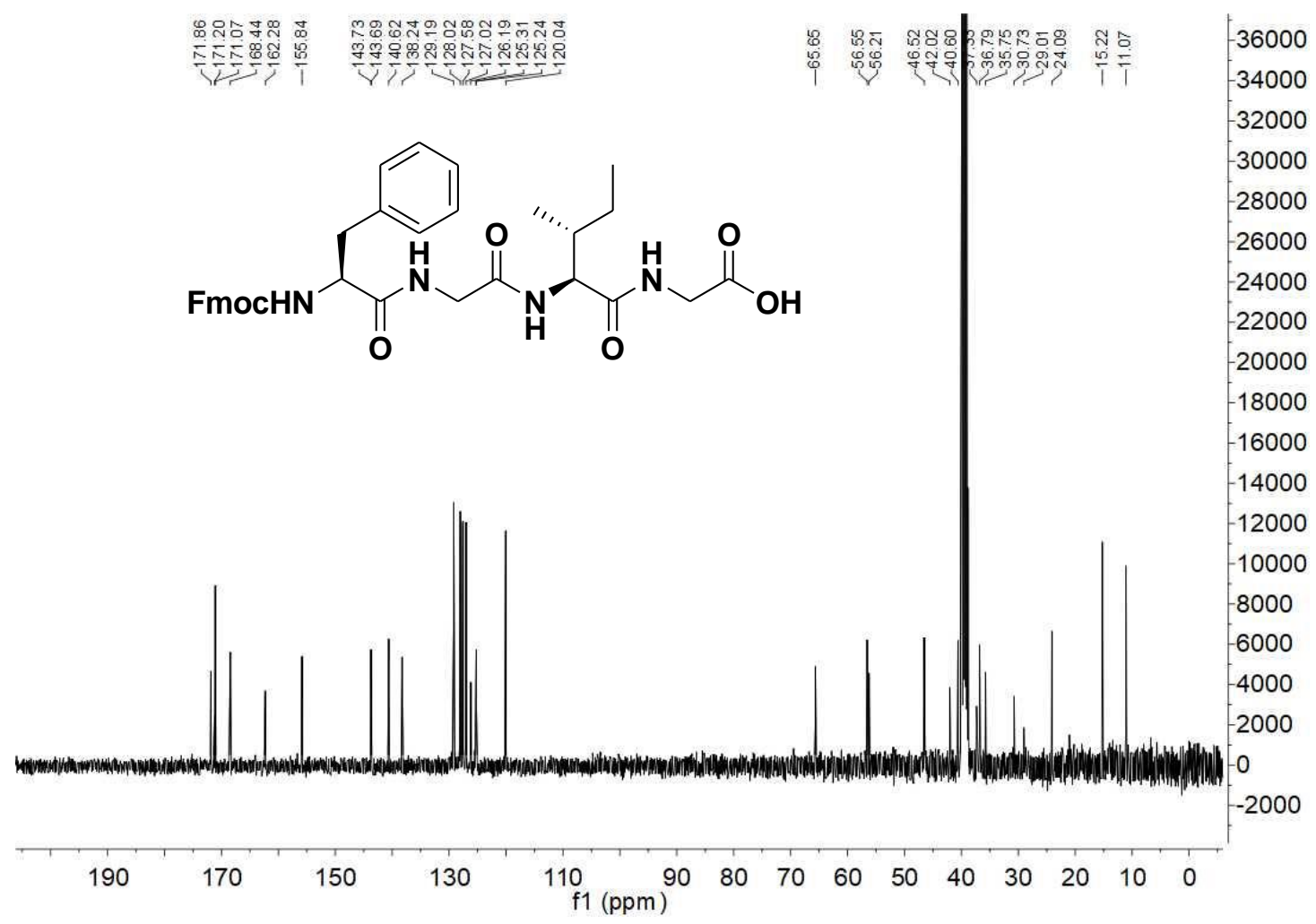

Figure S35. ${ }^{13} \mathrm{C}\left\{{ }^{1} \mathrm{H}\right\}$ NMR spectrum of compound 6 in DMSO at $125 \mathrm{MHz}$

IR

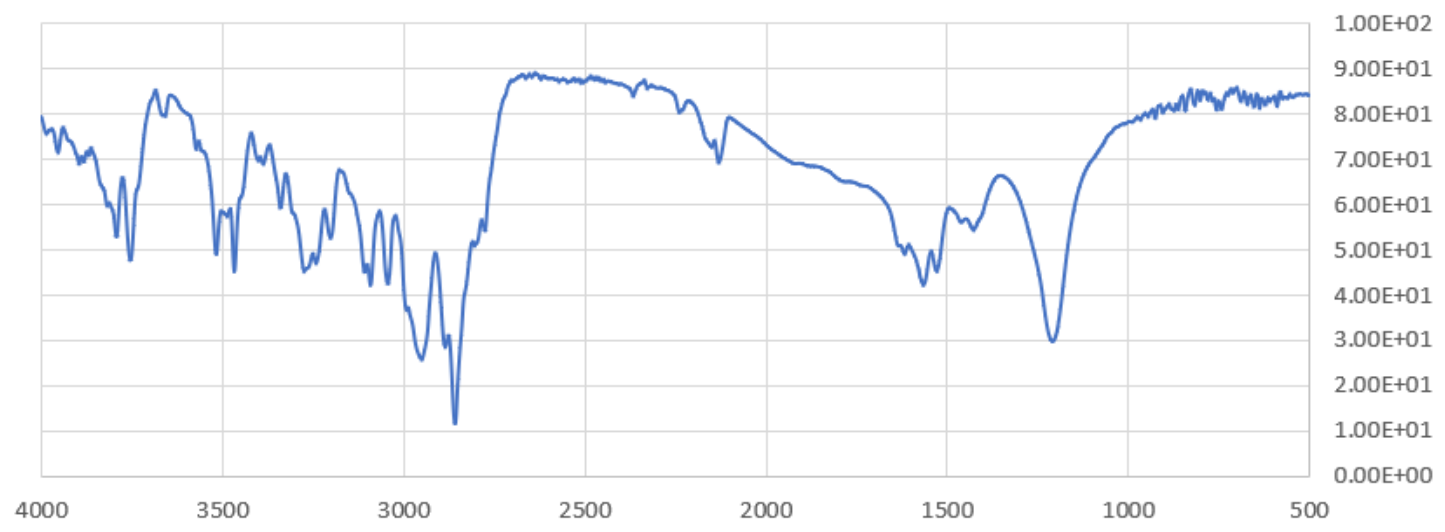

Figure S36. IR ( $\mathrm{KBr})$ Spectrum of compound 6 


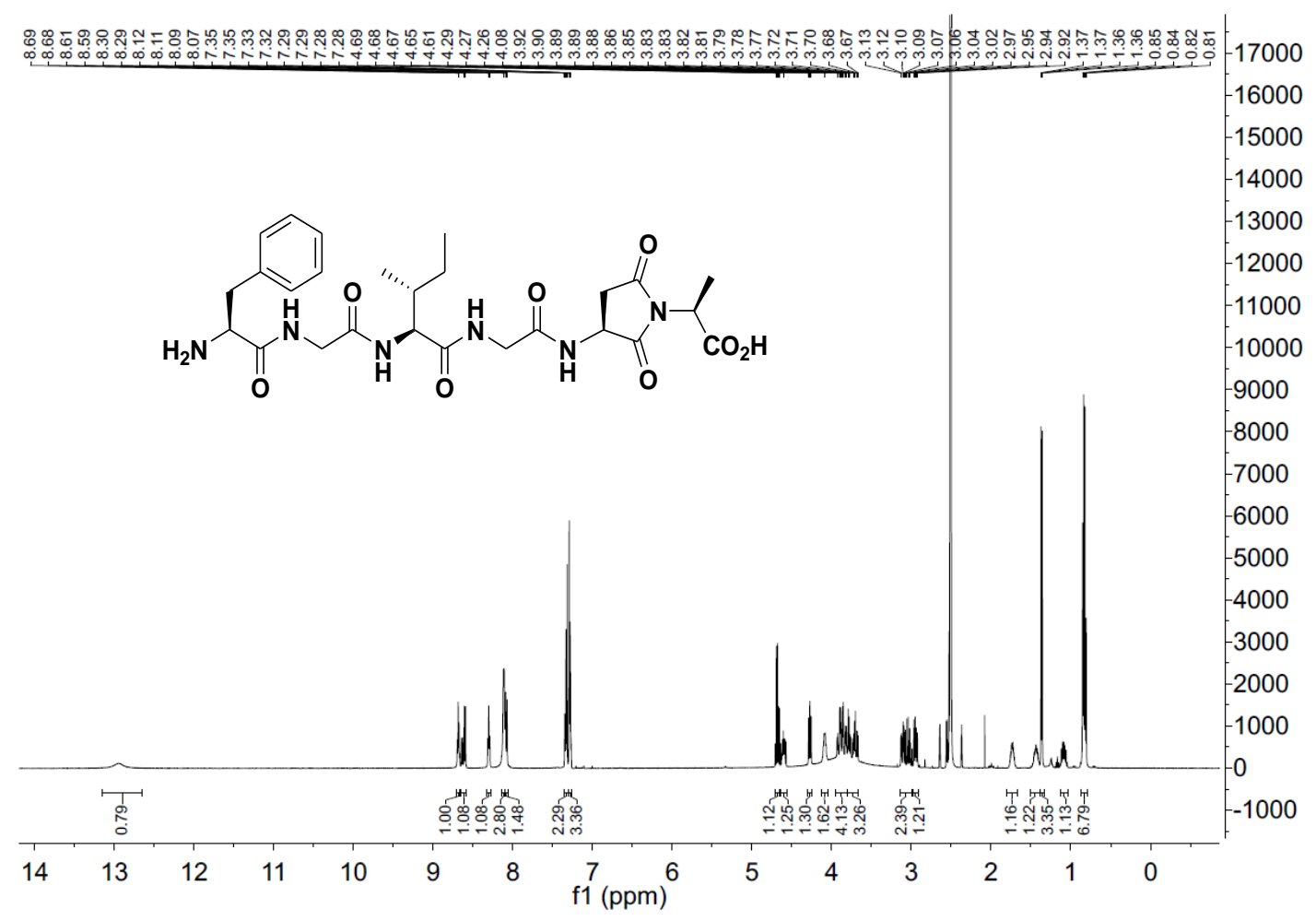

Figure S37. ${ }^{1} \mathrm{H}$ NMR spectrum of compound 7 in DMSO at $500 \mathrm{MHz}$

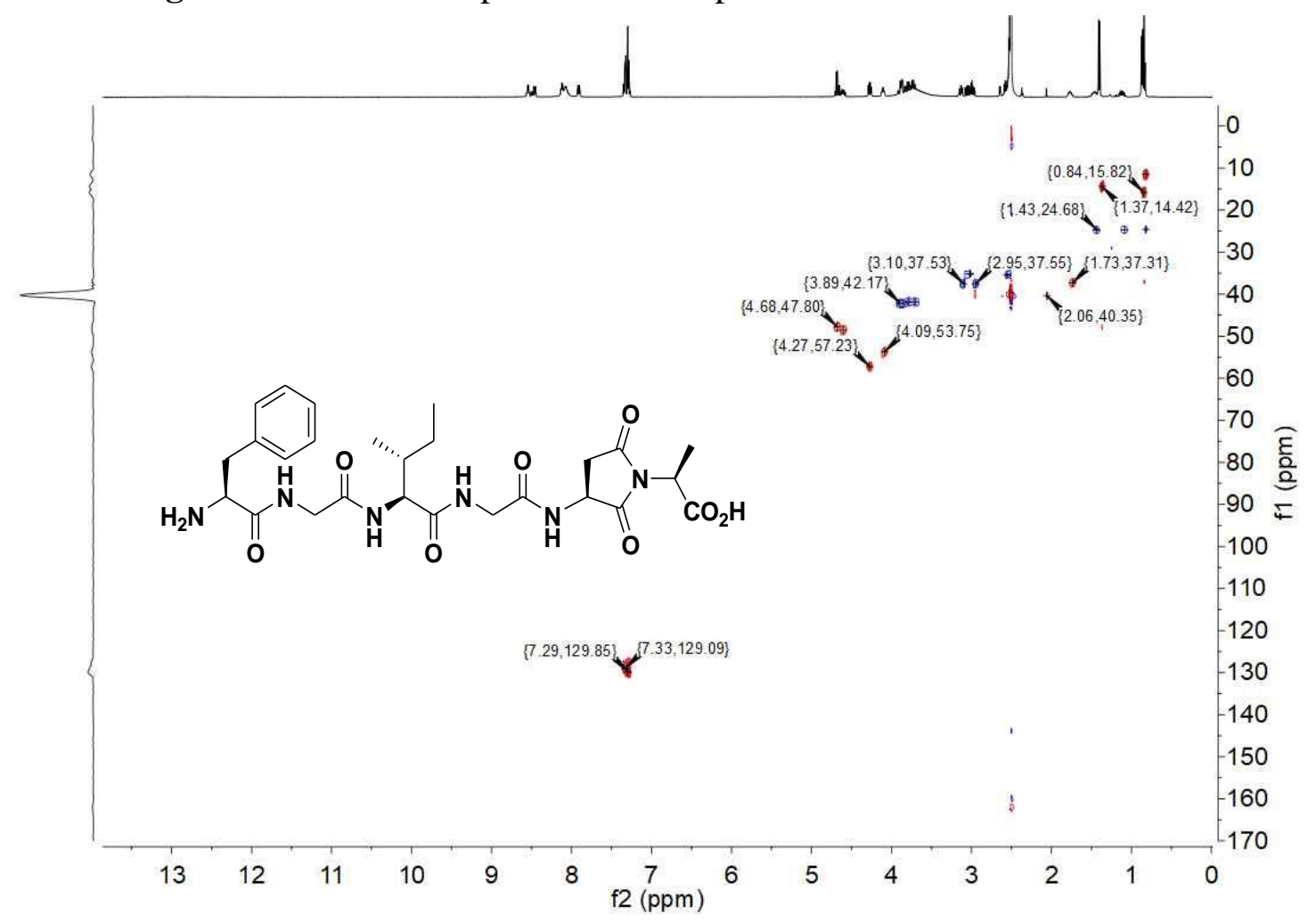

Figure S38. HSQC-ed $\left\{{ }^{1} \mathrm{H}_{-}{ }^{13} \mathrm{C}\right\}$ spectrum of compound 7 in DMSO at $500 \mathrm{MHz}$ 


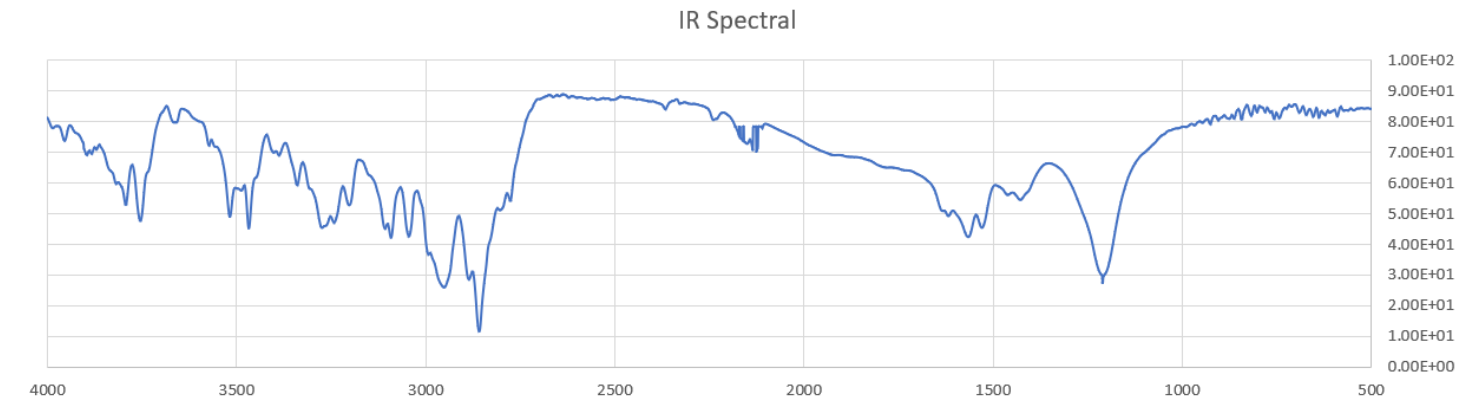

Figure S39. IR ( $\mathrm{KBr}$ ) Spectrum of compound 7

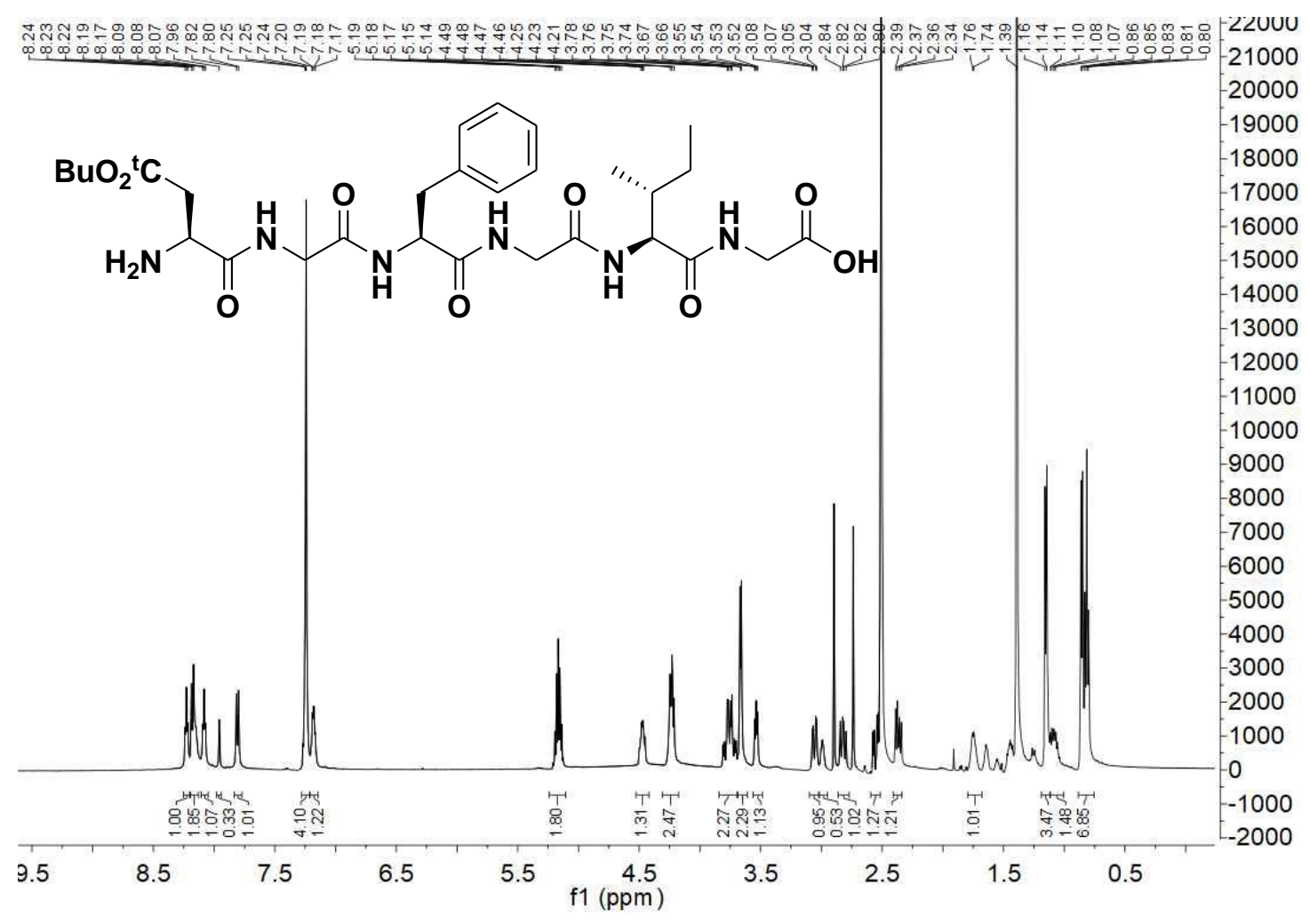

Figure S40. ${ }^{1} \mathrm{H}$ NMR spectrum of compound 8 in DMSO at $500 \mathrm{MHz}$ 


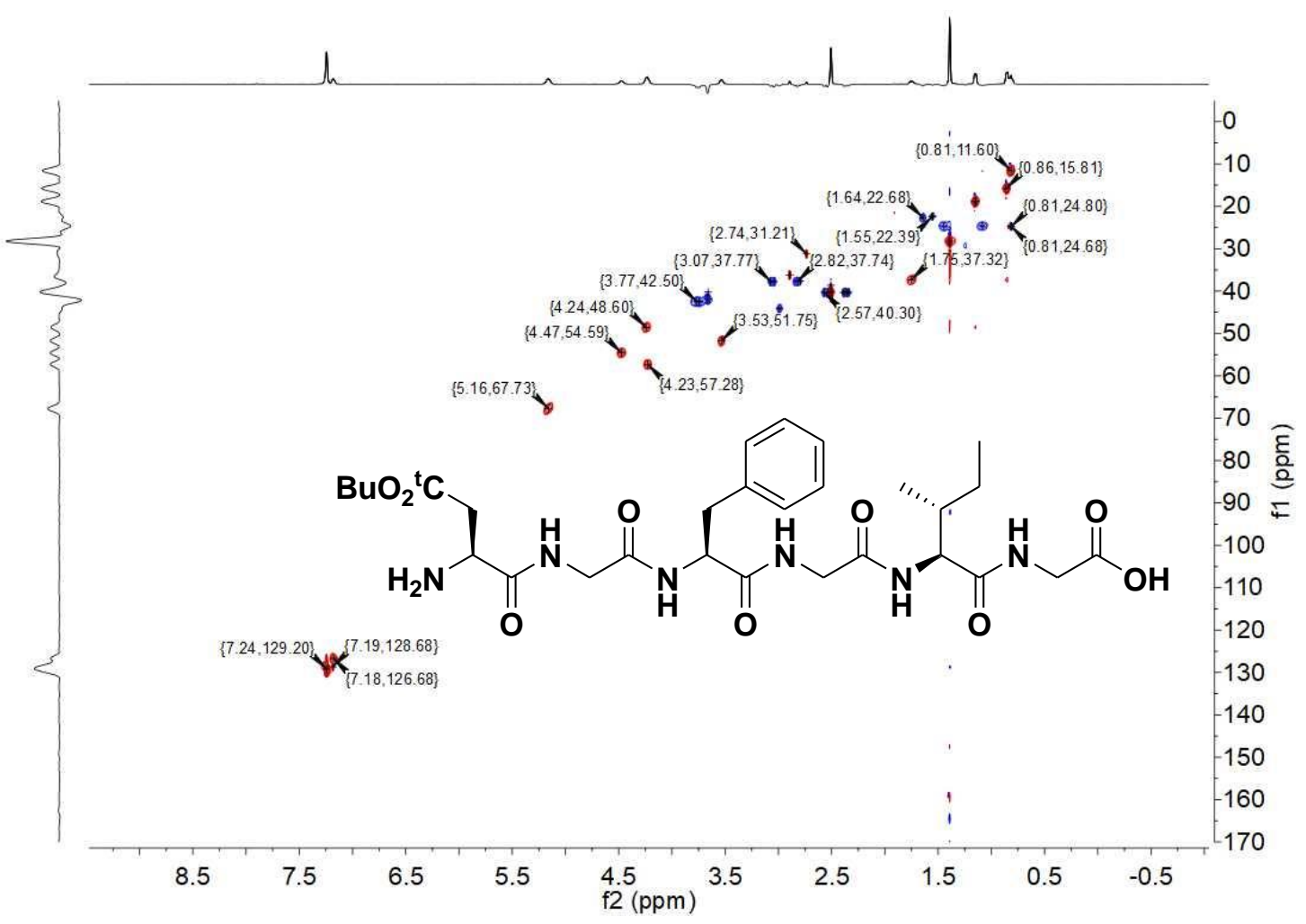

Figure S41. HSQC-ed $\left\{{ }^{1} \mathrm{H}^{-13} \mathrm{C}\right\}$ spectrum of compound 8 in DMSO at $500 \mathrm{MHz}$

IR Spectral

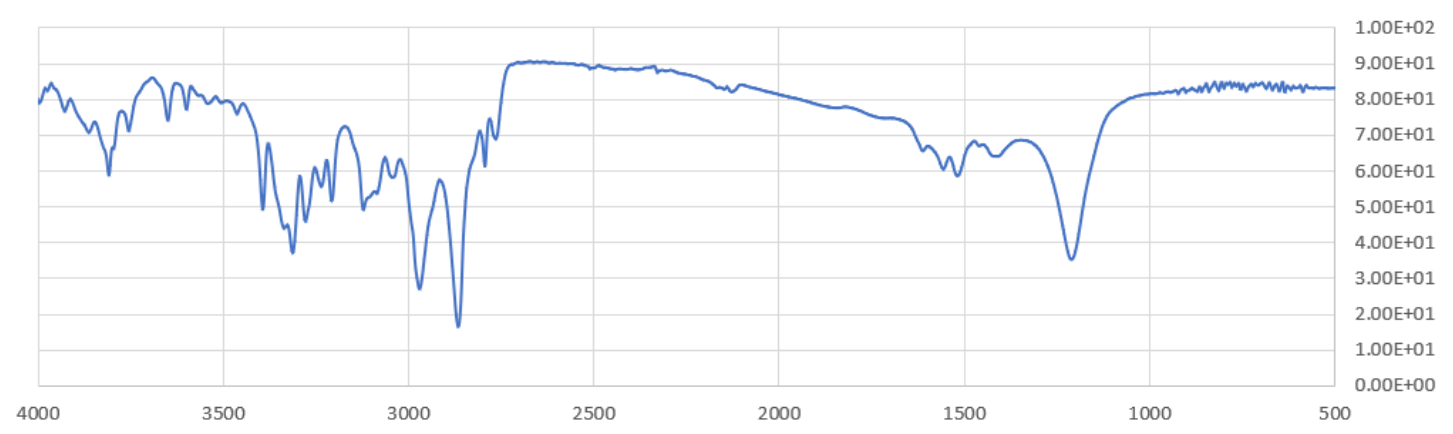

Figure S42. IR ( $\mathrm{KBr}$ ) Spectrum of compound 8 


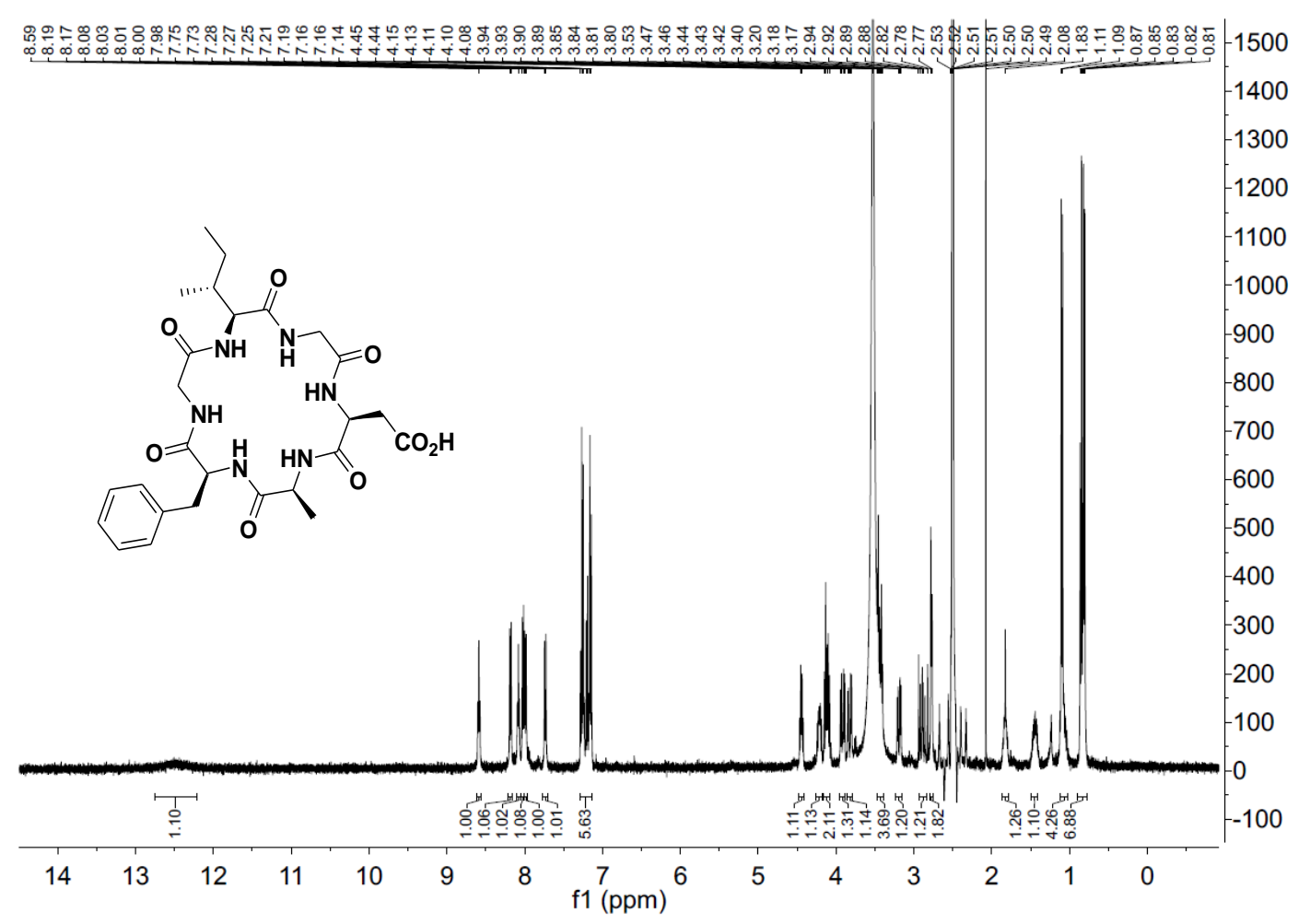

Figure S43. ${ }^{1} \mathrm{H}$ NMR spectrum of compound 10 in DMSO at $500 \mathrm{MHz}$

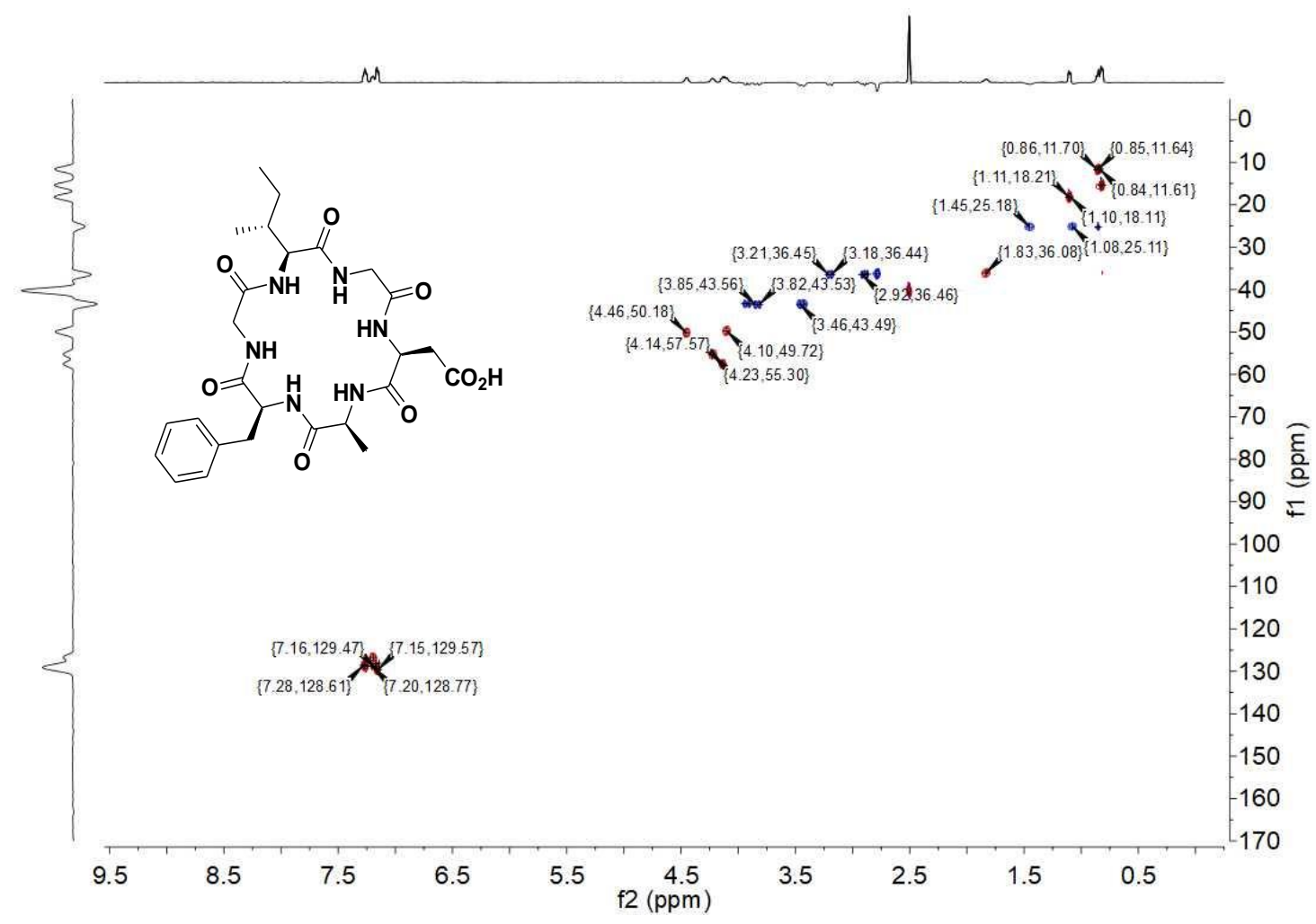

Figure S44. HSQC-ed $\left\{{ }^{1} \mathrm{H}^{13} \mathrm{C}\right\}$ spectrum of compound 10 in DMSO at $500 \mathrm{MHz}$ 
IR

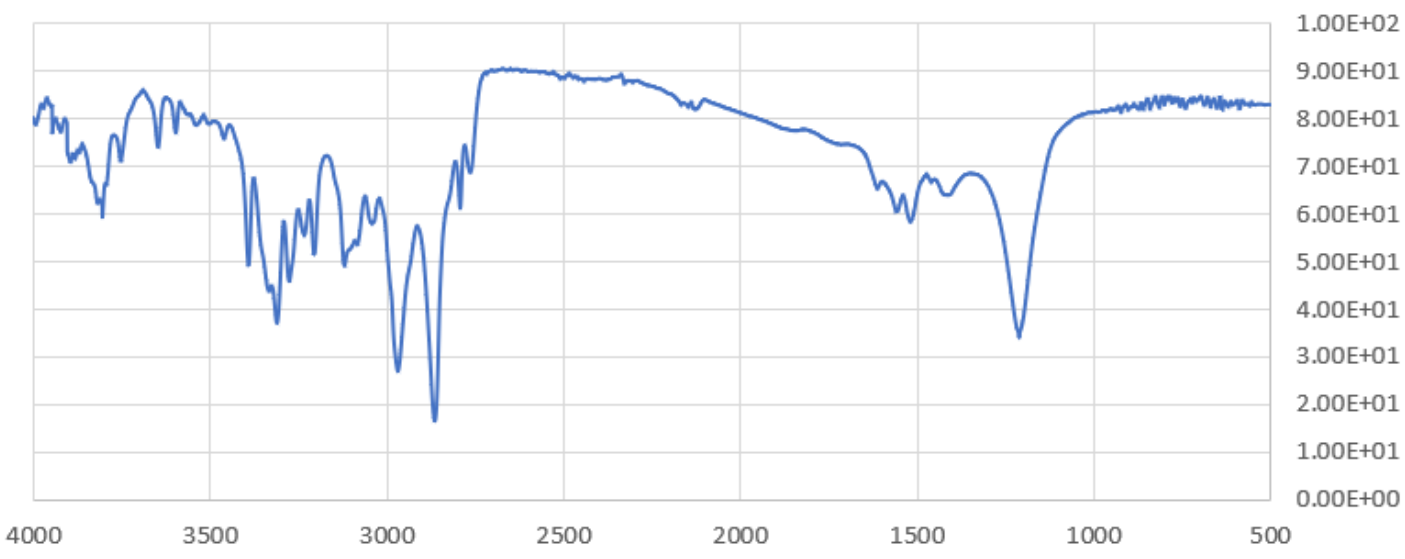

Figure S45. IR (KBr) Spectrum of compound 10 